\title{
و اقع التجول العقلي لدى طلبة الجامعة في العراق في ضوء بعض المتغيرات
}

\author{
زينة نزار وداعة \\ مدرس مساعد في قسم علم النفس - جامعة القادسية- العراق
}

Zina.aljanabi@qu.edu.iq

التجول العقلي هو فشل بعض الطلبة في الاحتفاظ بتركيزهم على أفكارهم وأنشطتهم الخاصية ذات العلاقة بالمهمة الحالية، ويكون هذا الفشل لترال

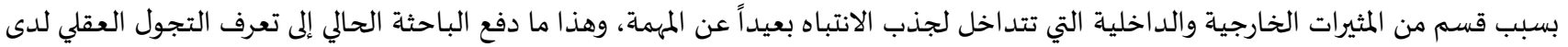

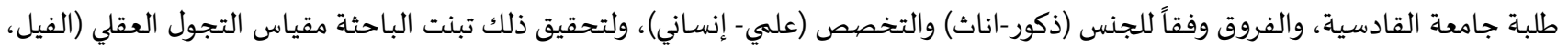

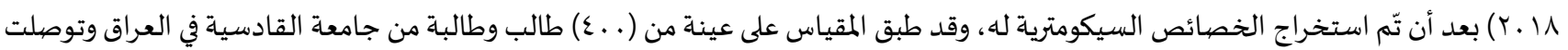

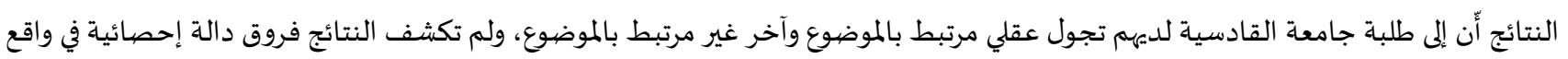

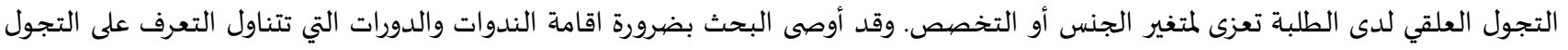
العقلي وسبل التخلص منه، وضرورة استدام مداخل مبتكرة في تدريس الطلبة والابتعاد عن الطرق الكلاسيكية.

الكلمات المفتاحية: التجول العقلي؛ الانتباه؛ طلبة جامعة القادسية.

\section{(9)}

المقّدمة:

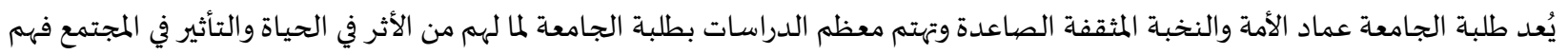

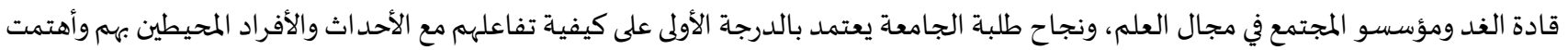

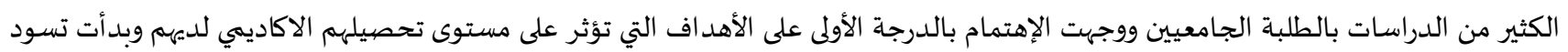

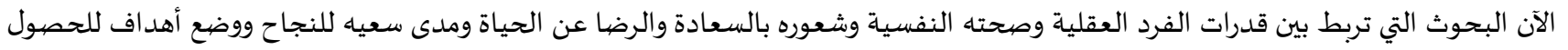

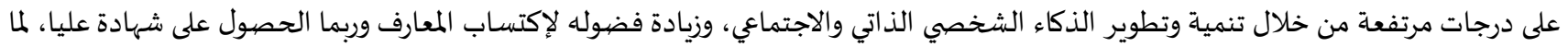

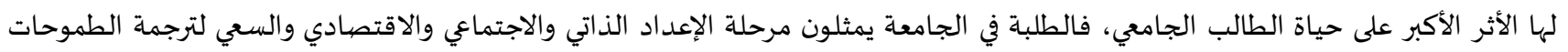

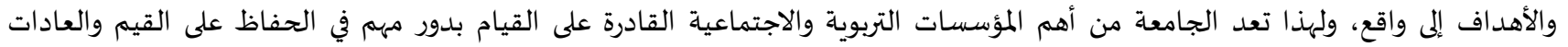

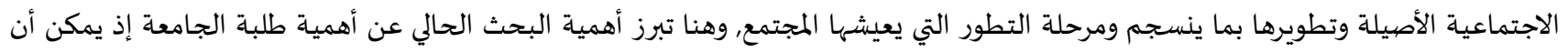

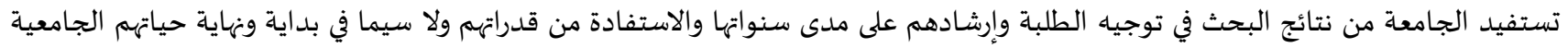

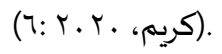

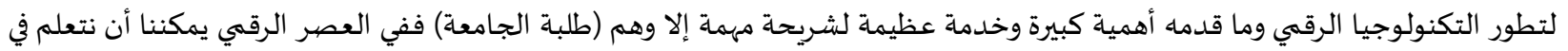

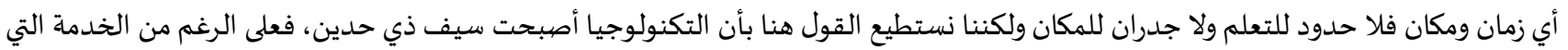

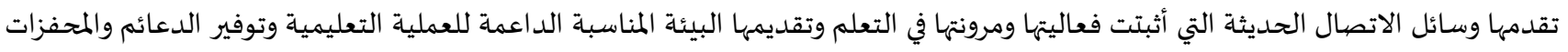

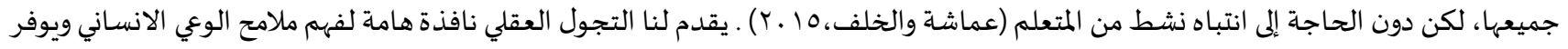

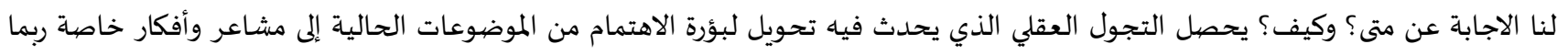

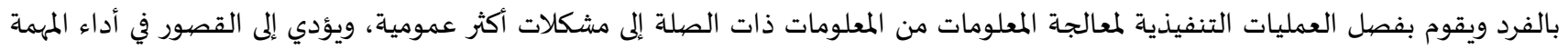


للتجول العقلي أهمية كبيرة ومن المتنبئ له بالعديد من الدراسات المستقبلية كنتيجة لانعكاساته وتأثيراته السلبية والآيجابية على العديد من الماتئ

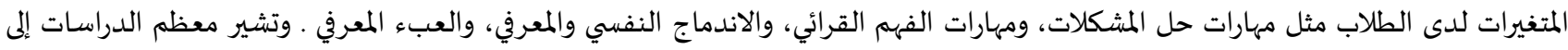

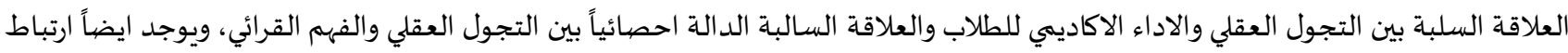

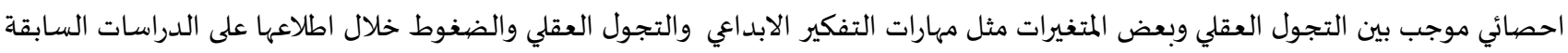

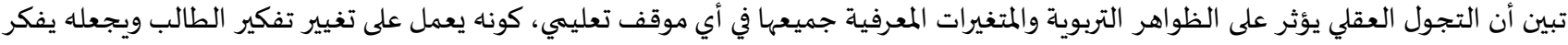

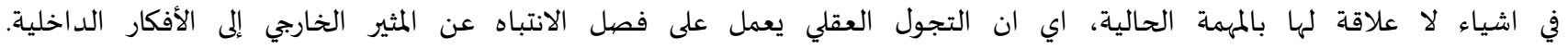

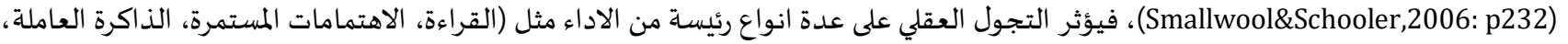

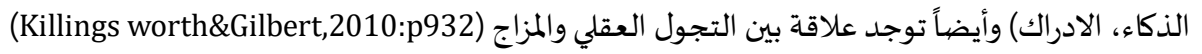

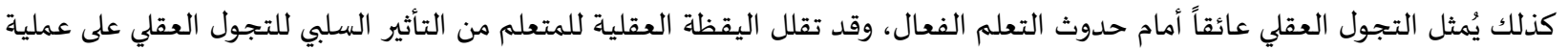

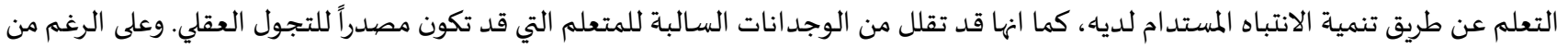

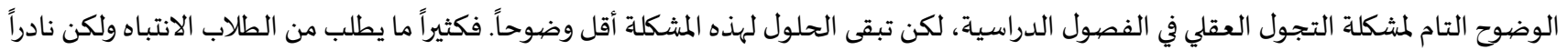
ما يتم تدريبهم على كيفية القيام بذلك، ومما يُزيد من هذه المشكلة هو اعتقاد الطلاب انفسهم بأن ميلهم إلى التجول العقلي وقدرتهم على تركيز الانتباه

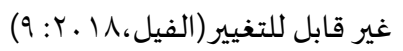
وبما أن تطور أي مجتمع يرتبط بمدى جودة العملية التعليمية فيه، فقد ترتب على ذلك إحداث تغيرات نحو التحو التربية، وزاد الاهتمام بدورها كأداة

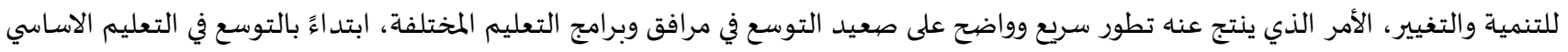

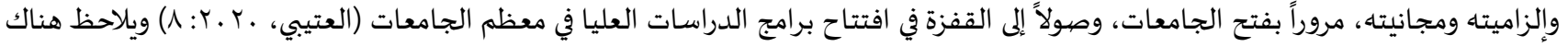

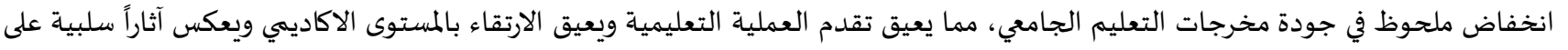

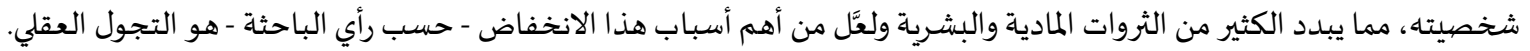

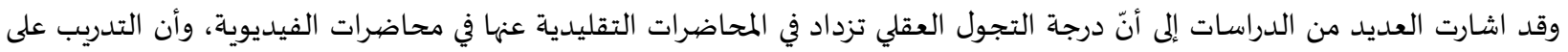

اليقظة الذهنية يُخفض من التجول العقلي لدى طلاب الجامعة (Rahl et al,2017: p230).

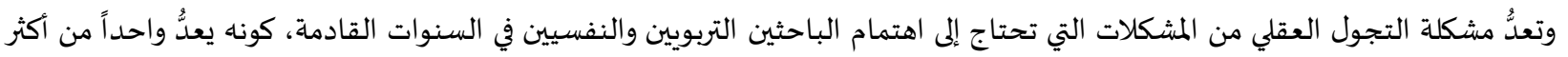

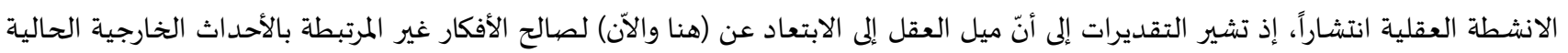

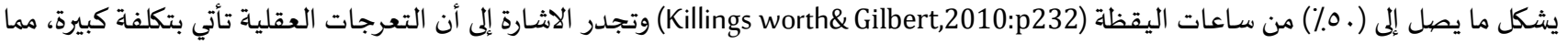

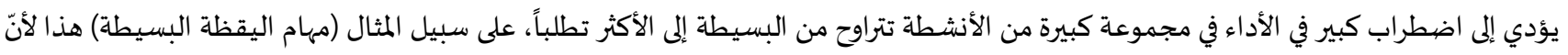

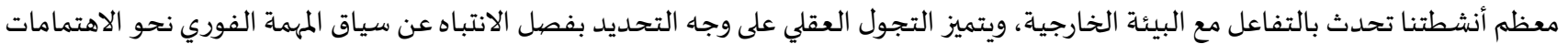

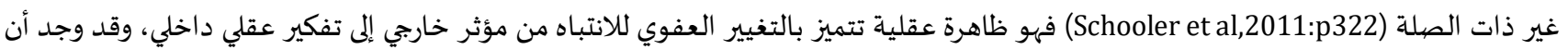

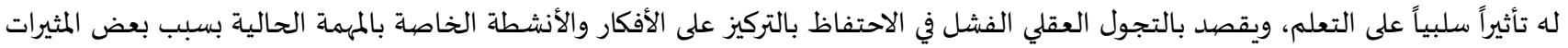

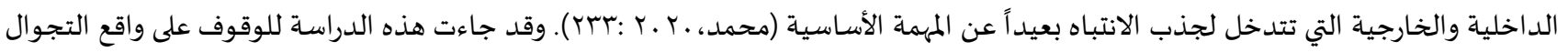

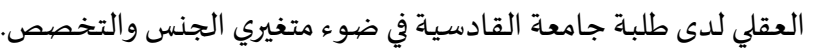

مشكلة البحث:

تتمثل مشكلة البحث في السؤال الرئيس التالي: ما واقع التجول العقلي لدى طلبة جامعة القادسية في العراق في ضوء بعض المتغيرات؟

أسئلة البحث: تتمثل أسئلة البحث في الآتي:

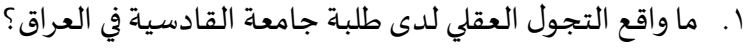

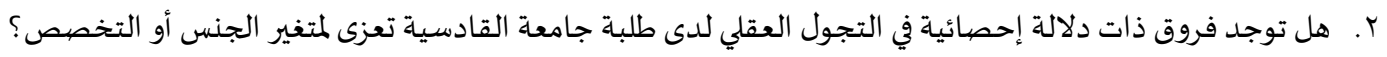
أهداف البحث: يهدف البحث الحالي إلى تعرف: 1. اقع التجول العقلي لدى طلبة جامعة القادسية. r. دلالة الفرق في التجول العقلي لدى طلبة جامعة القادسة على وفق متغيري الجنس والتخصص. 
أهمية البحث: يستمد البحث أهميته مما يلي:

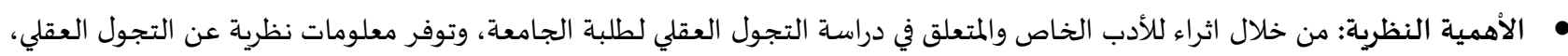

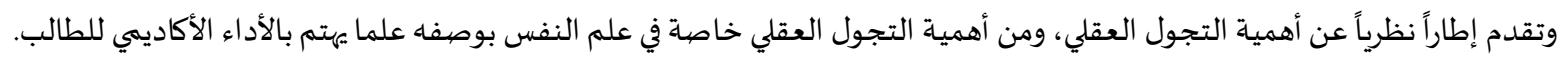

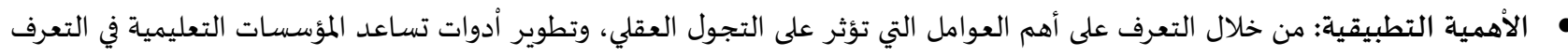

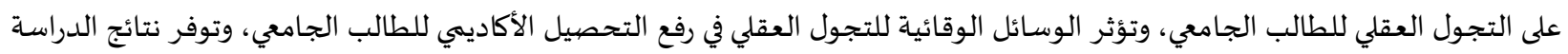

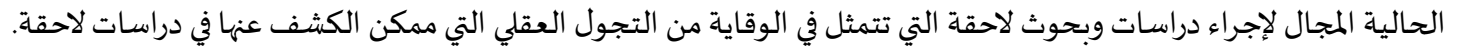

\author{
حدود البحث: يتحدد البحث الحالي بالحدود التالية: \\ الحد الموضوعي: التجول العقلي. \\ الحد البشري: طلبة الدراسة الصباحية في جامعة القادسة من كلا الجنسين. \\ بالحد المكاني: جامعة القادسية في العراق.

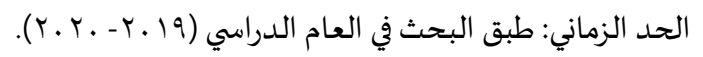

تعريف المصطلحات:

التجول العقلي: Mind-Wandering

عرفه ( Randall,2015) بأنّه الفشل في قدرة الفرد على الاحتفاظ بتركيزه على أفكاره وانشطته الخاصة ذات العاتئل العلاقة بالمهمة الحالية ويكون هذا

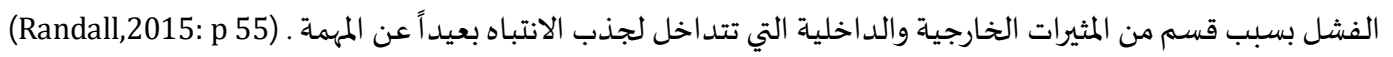

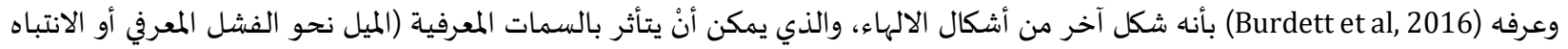

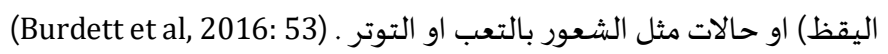

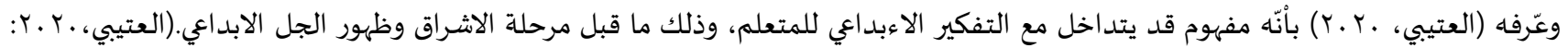

وعرفة (الفيل، 11 ـ ب) بأنه تحول تلقائي في الانتباه من المهمة الاساسية إلى أفكار أخرى داخلية او خارجية وهذه الأفكار قد تكون مرتبطة بالمهمة

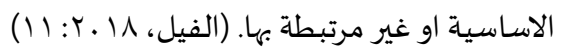

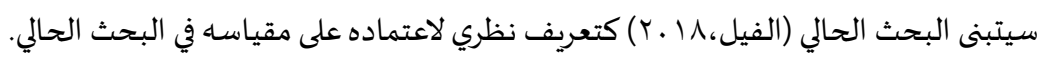

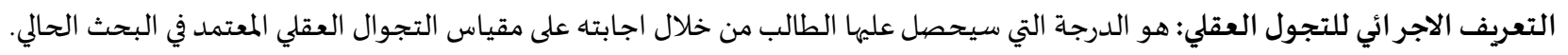

الإطار النظري:

بيّن سمث وآخرون (Smith,et al) أنّ الانخفاض الواضح في الانتباه يؤثر على قدرة الأشخاص على حل المشكلات (Smith,et al,1993:P193) ويُعطى الدور هنا إلى الانتباه التنفيذي بعده الآلية المسؤولة عن إدارة المصادر المعرفية للعمليات المستمرة (Engle,et al,1999:p125) ويساهم الإنئ الانتباه

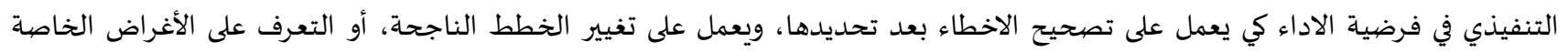

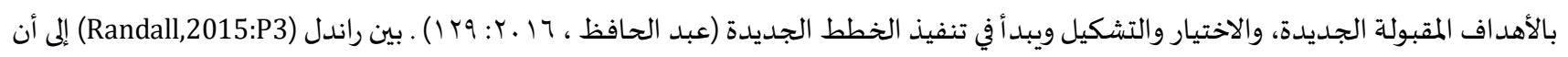

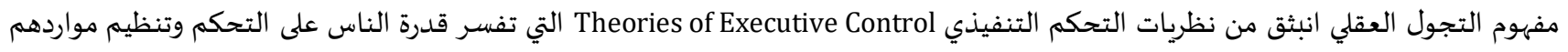

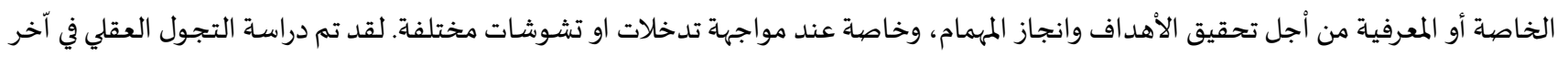

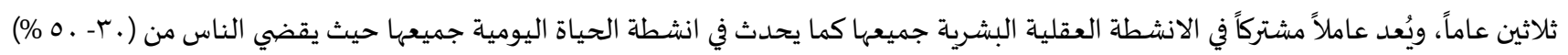

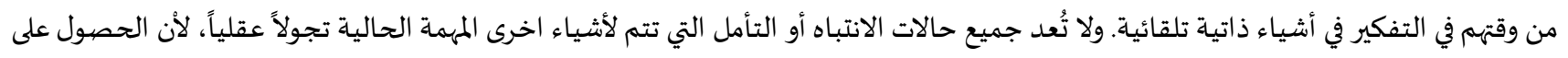

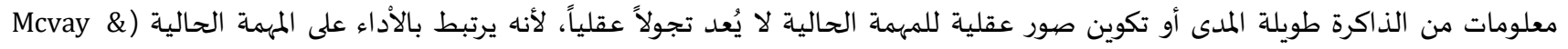

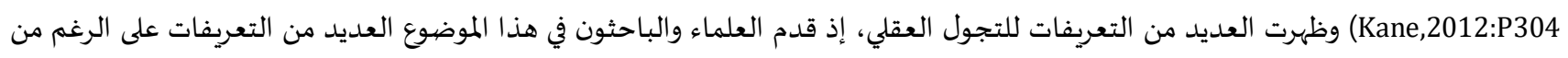

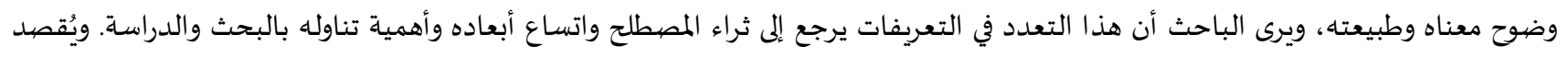

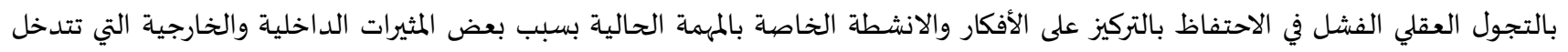

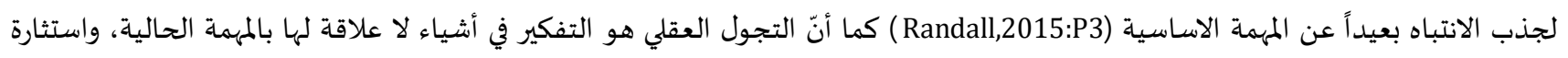

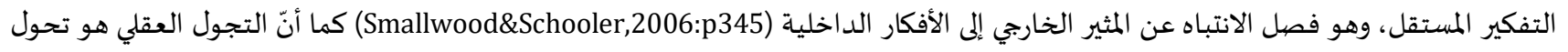




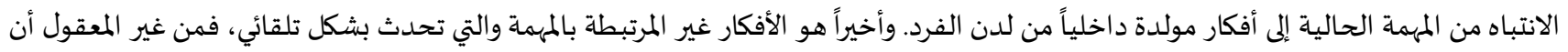

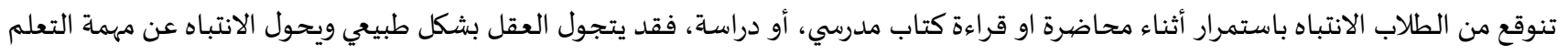

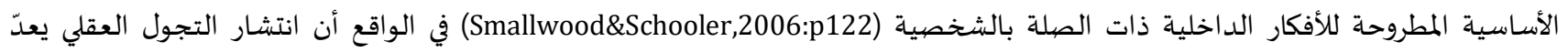

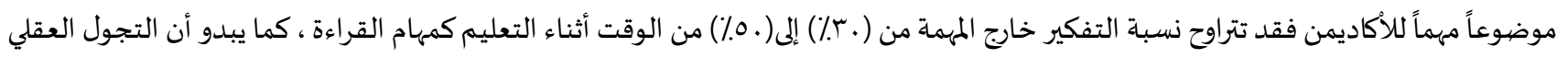

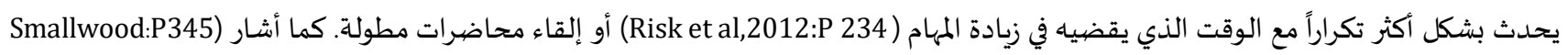

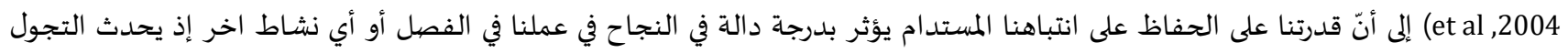

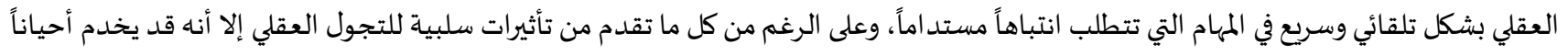

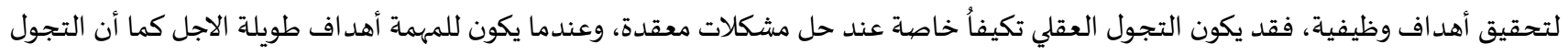

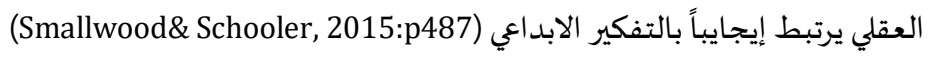

$$
\text { يوجد نواع التجول العقلي: }
$$

ا. التجول العقلي المرتبط بالمادة الدراسية: هو انقطاع التجاع اجباري في الانتباه إلى أفكار غير مرتبط بالمهمة الحالية ولكنها مرتبطة بموضوعات المادة

$$
\text { الدراسية التي تحدث بشكل تلقائي. }
$$

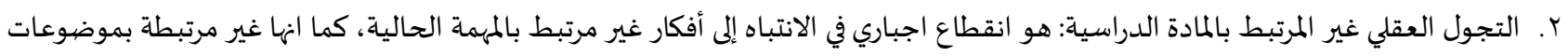

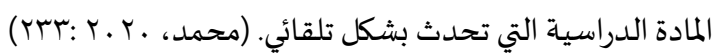

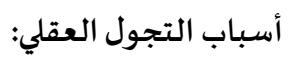

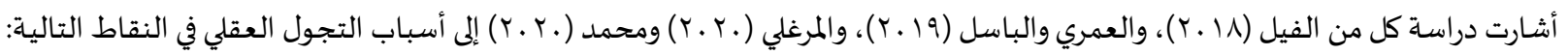
السعة العقلية المحدودة: وهذا يرجع إلى انخفاض الوظائف التنفيذية للذاكرة وانخفاض مطالب المهمة.

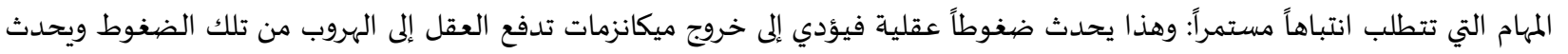

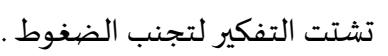

• الحالة المزاجية : الحالة المزاجية السالبة تؤدي إلى التجول العقلي أكبر من الحالة الموجبة أثناء التفكير في المهمة.

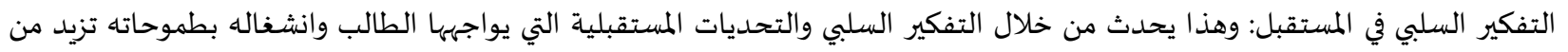
التجول العقلي. التنبؤات السلبية: مثل النعاس والاجهاد والأنشطة الإلزامية، وفروض الفصل الدراسي تظهر التجول العقلي وتصرف تفكيرهم بشكل كلي إلى أفكار أخرى خارج المهمة. • التنبؤات الايجابية: مثل السعادة، والكفاءة، والتركيز، والتمتع بالاشياء، وتصرفات تفكير الطلاب عن المهمة الرئيسة المكلفون بها، وزيادة دافعيتهم والرغبة في انجاز المهمة. التنؤات العميقة: مثل الأنشطة الصعبة، المهام التي تحتاج إلى تفكير وتخطيط، والتي تتطلب اتخاذ قرارات والتحدي للطلاب انفسهم وقدراتهم على القيام بتلك المهمام والانشطة. وتحتل الأفكار التي تمثل محتوى التجول العقلي اهتمام الباحثين في الوقت الحالي وتصنف الأفكار إلى:

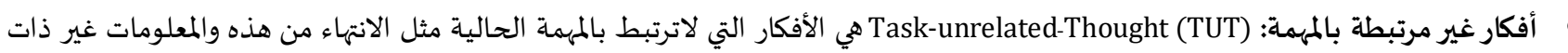

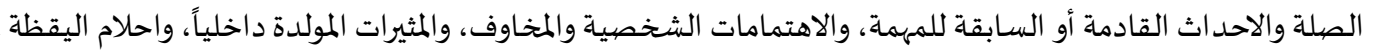

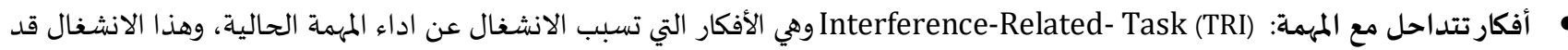

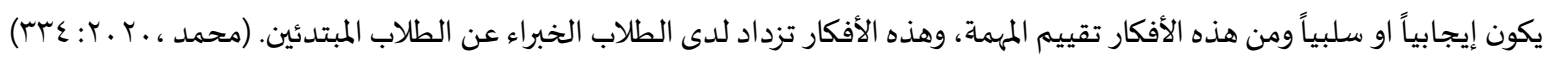

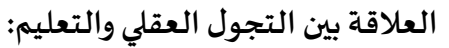
من الواضح أنّ التقدم في التعلم يعتمد على الطلاب من خلال القدرة على دمج المعلومات من البيئة الاجتماعية مع تمثيلاتها الداخلية (الخاصة). ومن أسباب التجول العقلي ذو الصلة بالتعليم هي:

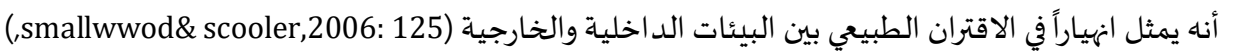


• عندما تتجول عقول الناس، يتوقف تركيز الوعي عن اشراك البيئة الخارجية بطريقة هادفة.

ه يحدث عندها شروداً للذهن كجزء من تدفق طبيعي لتجربة الشخص الخاصية (البيئة الداخلية)

• وتجول العقل بشكل طبيعي وينتقل الانتباه من مهمة التعلم المطروحة إلى الأفكار الداخلية ذات الصلة بالشخصية.

هحدث التجول العقلي بشكل متكرر مع زيادة الوقت الذي نقضيه في مهمة ما. (Kane\& Mcvay, 2012:304)

علاقة التجول العقلي بالذاكرة العاملة:

أحد الاسئلة المهمة التي تواجه دراسة التجول العقلي هو كيفية ارتباطها بسعة الذاكة العرة العاملة، درست الابحاث الحديثة العلاقة بينهما إذ تمثل

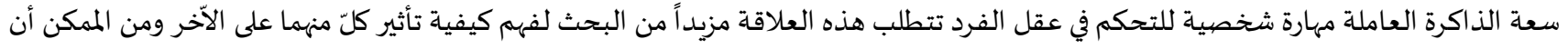
يتسبب التجول العقلي في انخفاض الاداء في مهام سعة الذاكرة العاملة أو أن انخفاض سعة الذاكرة العاملة، يسبب المزيد من حالات التجول العقلي. (Kane,2012:p348) وعلى الرغم من هذا الأخير فقط قد تم اثباته بالفعل. أيضاً تكون تقارير الأفكار غير المتعلقة بالمهمام أقل تكراراً عند أداء المهمام

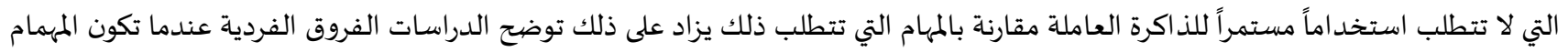

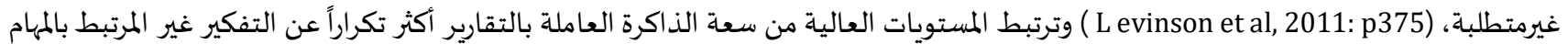

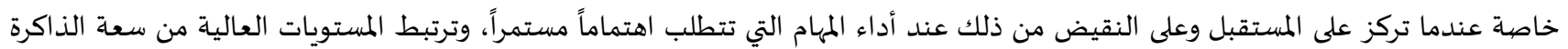

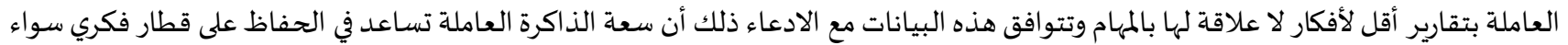

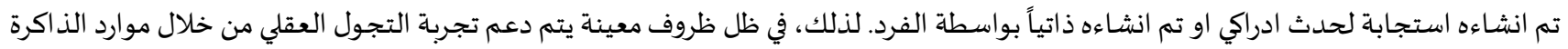

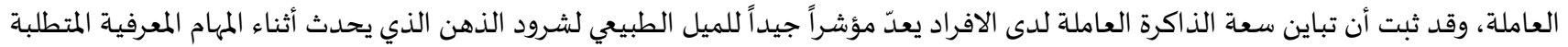

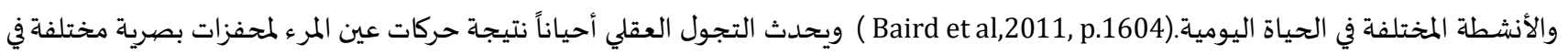

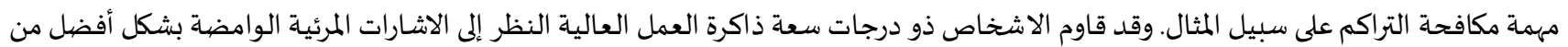
المشاركين ذو سعة ذاكرة عمل المنخفضية. وترتبط سعة ذاكرة العمل المرتفعة بعدد أقل من الرموز اتجاه الاشارات البيئية لقد ثبت ان شرود المهاد الذهن

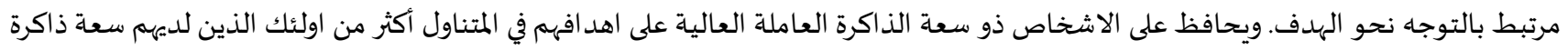

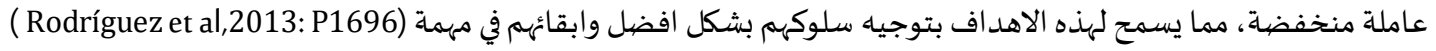

استر اتيجيات تقليل التجول العقلي في الأوساط التعليمية: الحصول على فترات راحة منتظمة، مع مراعاة قيود النظام المعرفي.

دمج اسئلة (Checkpoint) من خلال المحاضرات، وهو الاختبار المعروف ايضاً بأسم ممارسة الاسترجاع ويساعد هذا الاختبار بشكل كبير على المأى الاحتفاظ يقوم الطلاب بترسيخ المعرفة من خلال الاسترجاع، وتحديد الفجوات المنطقية، وتعزيز الاحتفاظ بالمعلومات على المدى الطويل.

(Kane\& Mcvay, 2012b:302)

• تعزيز التعلم النشط من المناقشـات أو نشاطات أخرى، كما وتشمل استراتيجيات التعلم النشط استخدام التقنيات التي تعزز مشـاركة الطلاب مع

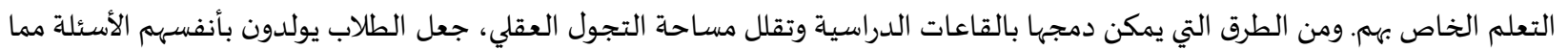
يؤدي إلى تحسين الانتباه اثناء المحاضرات.

• تشجيع الطلاب على تدريب التأمل اليقظ من خلال الحرم الجامعي أو الموارد عبر الانترنت، يعد التأمل اليقظ هو حل للعديد من قضايا الانتباه

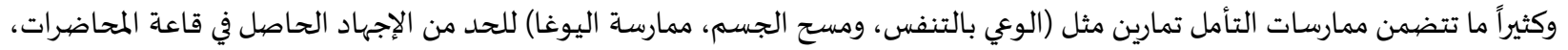

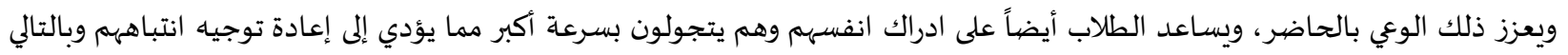
تقليل وقت التعلم. السمح للطلاب بالتفكير في التجول عندما لا يؤثر بشكل كبير على التعلم. من غير المحتمل ان يتم القضاء على تجول العقل بالكامل في موقف

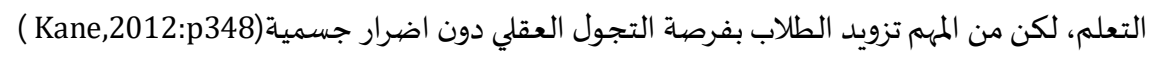

نظريات التجول العقلي:

ا. الأنموذج العصبي للتجول العقلي: Aneural moael of mind Wandering: يرتبط التجول العقلي مع التعديل العصبي عبر نظام النوبينفرين الموضعي. هنا نقترح أ- نموذج عصبي يربط بين النظامين في اطار تكاملي يحاول

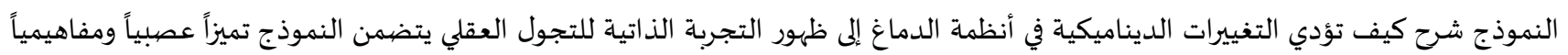


بين حالة خارج التركيز وحالة التجول العقلي النشطة، وتوفر اساساً عصبياً محتملاً لما يعرف جيداً النظريات المعرفية للتجول العقلي. Forster \&) Lavi, 2013:p1037)

إنّ التجول العقلي، أو الانخراط في مجموعات من الأفكار التي لا علاقة لها بأهداف المهمة الحالية (أو غير مفيدة) شائعة بالحياة اليومياة، في

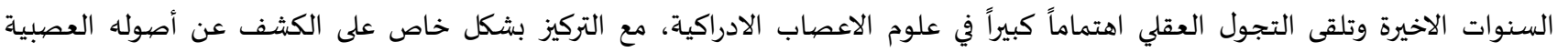

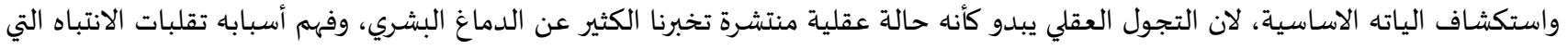

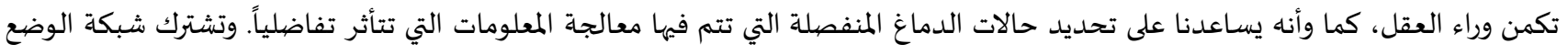

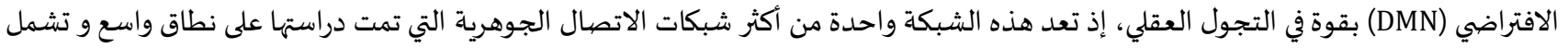

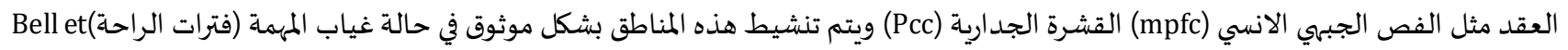

( al,2006:p466)

وتشارك (DMN) أيضاً في السيرة الذاتية، والتخطيط، والأفكار الموجهة داخلياً، بشكل عام يكون النشاط في عقد DMN الاساسية، هو يرتبط الخال

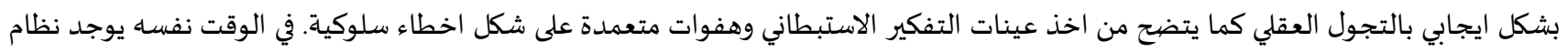

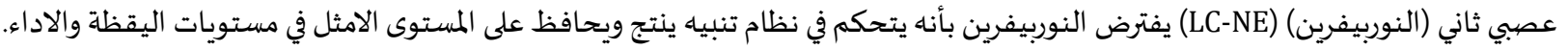

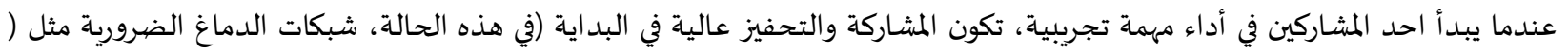

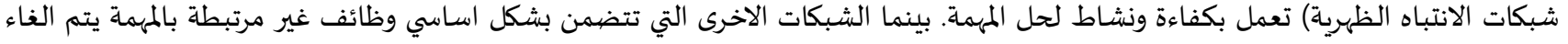

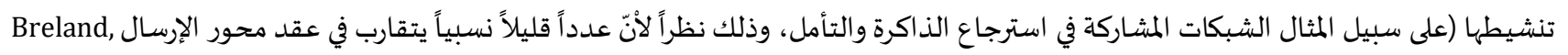

(2004:p 433).

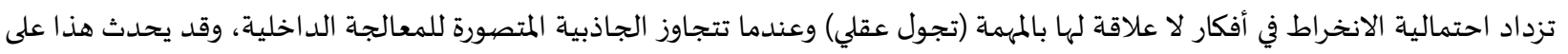

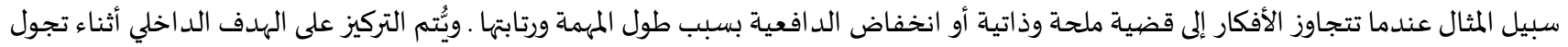
العقل بنسبة أكبر من الهدف الخارجي. وتتوافق (IcN2) مع الوظائف وتشارك في السعي لتحقيق الهدف بشكل أساسي . اثناء التجول العقلي يتم تقليل الاتصال الوظيفي بسبب المشاركة

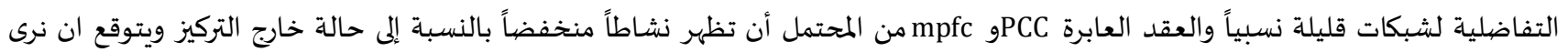
(Forster \& Lavie, 2009:p345) . LC- NE اندفاعات عابرة لنشاط

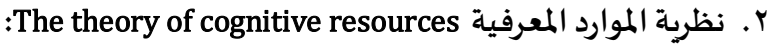

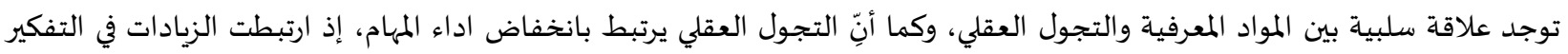

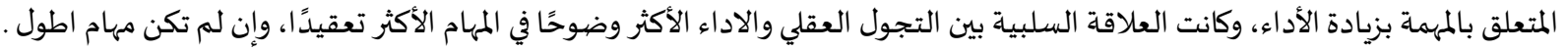

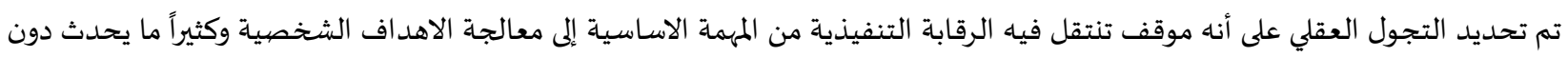

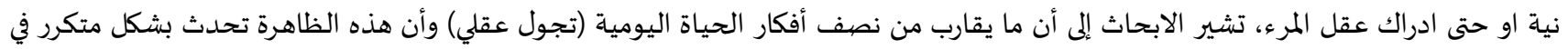

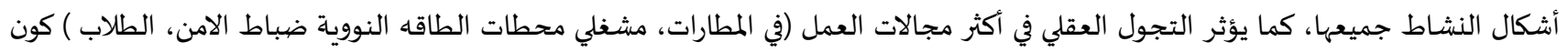

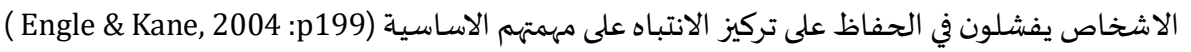

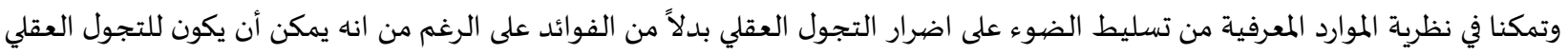

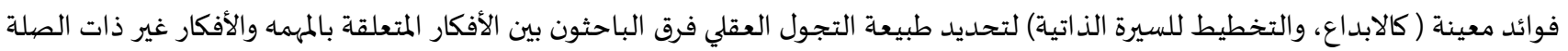

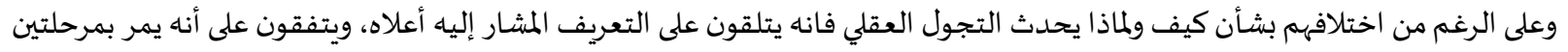

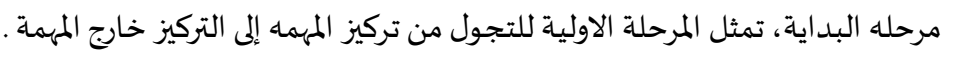

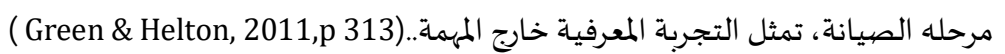

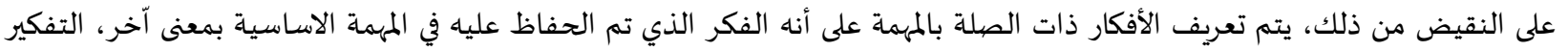

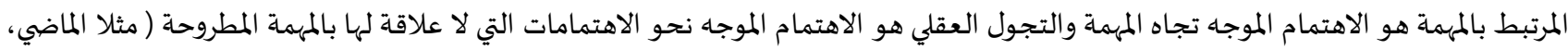
الاهداف المستقبلية) لخص سمولوود (2013) في ضوء التعريف المتفق عليه أربع فرضيات أولية حول العمليات المعرفية المشاركة في التجول العقلي الأول هو المخاوف

(Engle \& Kane, 2004 :p199). الحالية 


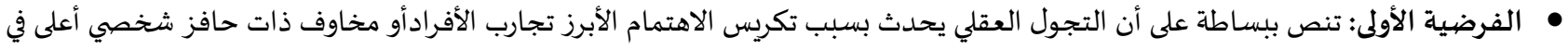

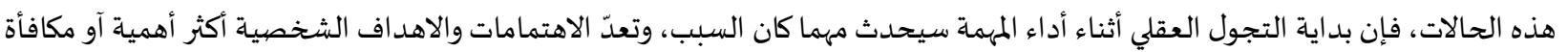

$$
\text { في المهمة التي يتم تنفيذها. }
$$

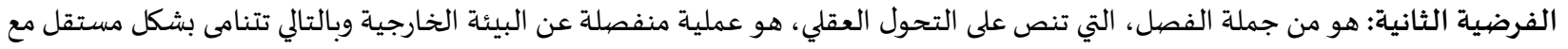

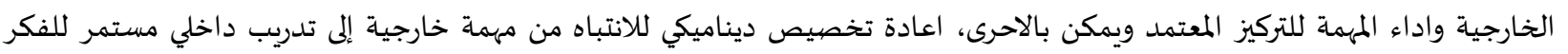

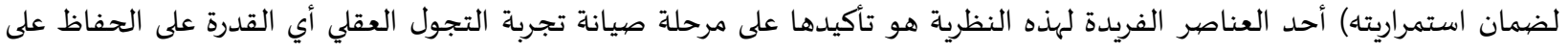

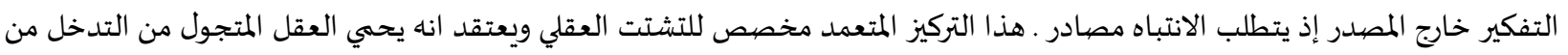

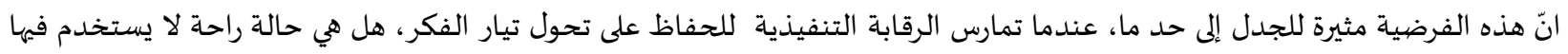
الرقابة التنفيذية او الموارد المعرفية (على سبيل المثال شبكة الدماغ ذات الوضع الافتراضي) (McVay \& Kane ,2012b:p141) الفرضية الثالثة: تكون هذه الفرضية حول طبيعية التجول العقلي هي فرضية (الفشل التنفيذي) الذي يقترح أنّ التجول العقلي يمثل الهاء أو أو التهاء

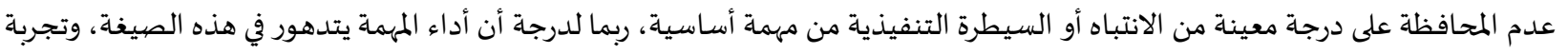

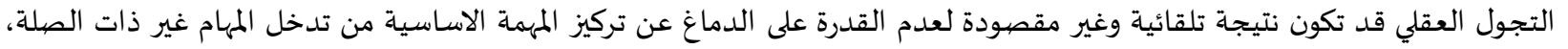

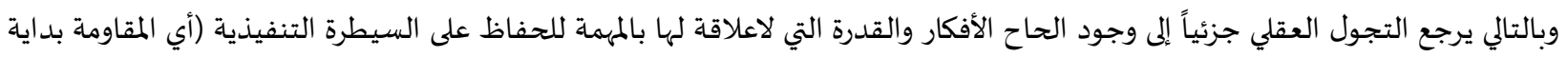

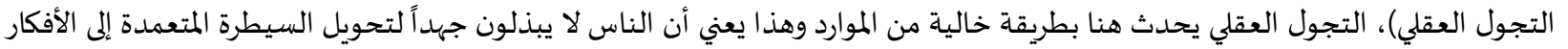

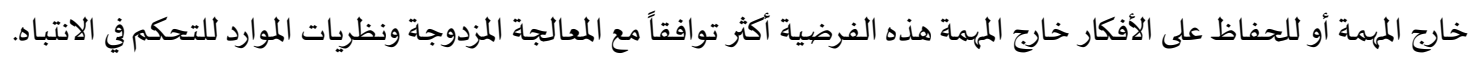

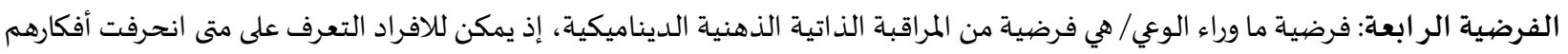

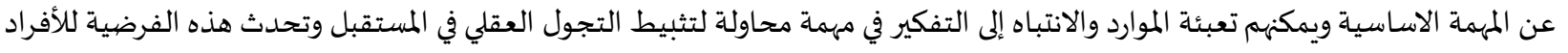

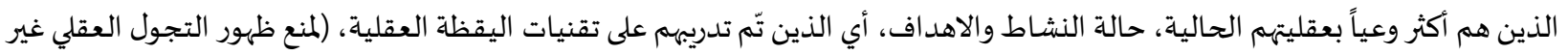

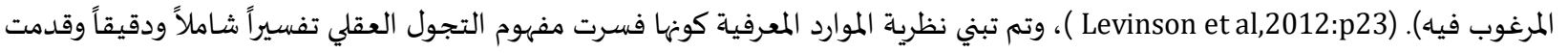

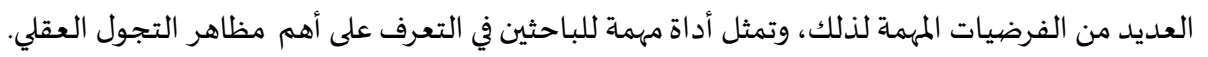

\section{فو ائد التجول العقلي:

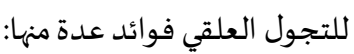
ا. مساعدة الأفراد على التخطيط للمستقبل، أن التركيز الزمني لأفكار الزمنية لأفكار المتجولين عقلياً يركز في الغالب على المستقبل أكثر من تركيزه

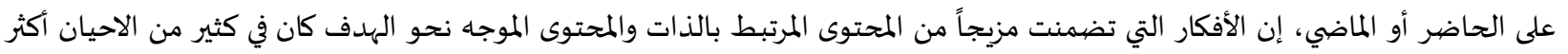

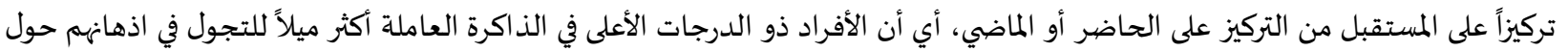

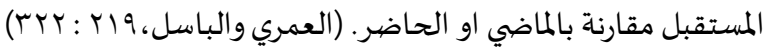

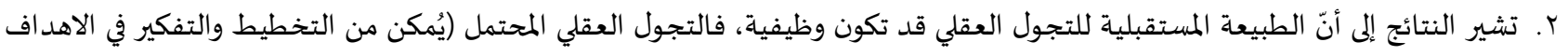

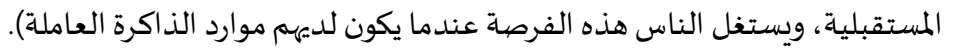

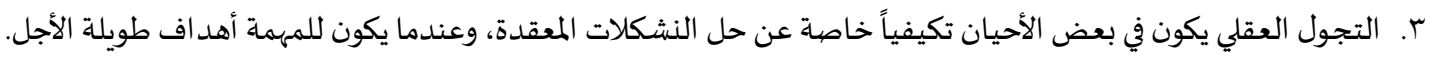

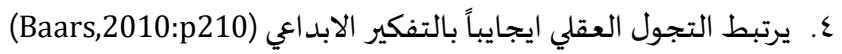

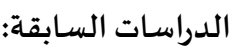

نظراً لأهمية التجول العقلي لدى طلبة الجامعات، فقد تناولته العديد من الدراسات الأجنبية والعربية مع متغيرات أخرى منها:

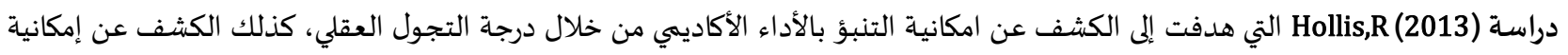

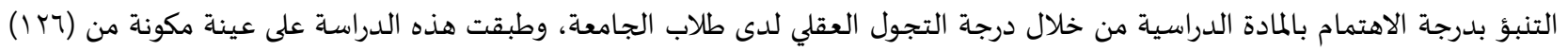

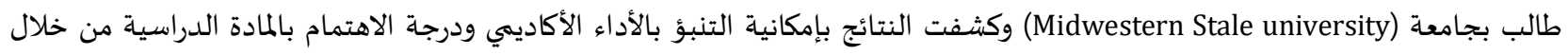
درجة التجول العقلي لدى طلاب الجامعة.

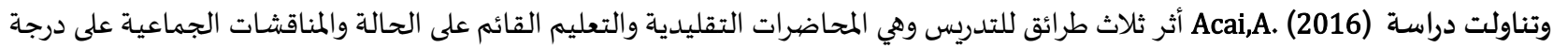

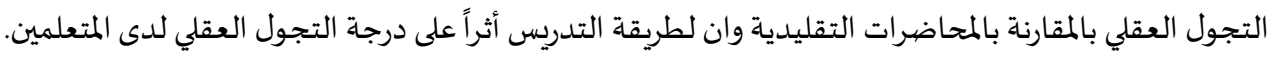


• كذلك كشفت دراسة Luo et al,(2016 إلى التأكد من صدق استبيان التجول العقلي، والتعرف، على العلاقة بين التجول العقلي والرضا عن

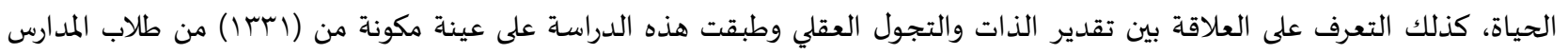

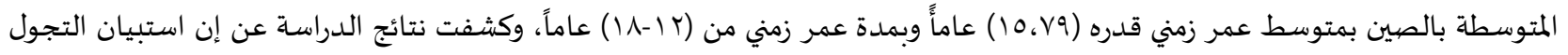

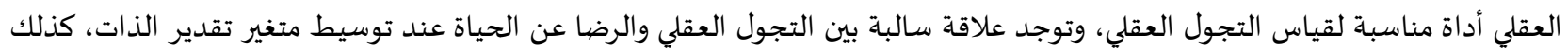
وجدت علاقة سالبة بين تقدير الذات والتجول.

هما تناولت دراسة (2017). Rahal,H.,Lindasay,E.,Pacilio,L.,Brown,K., \&Creswell,J) إلى التعرف على تأثير التدريب على اليقظة العقلية في

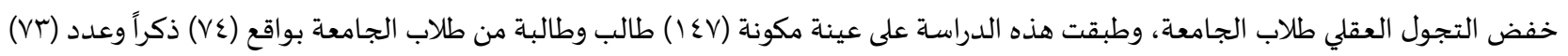

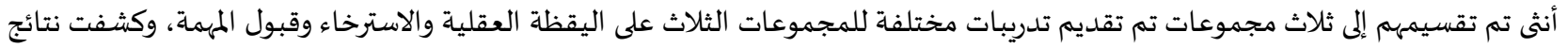

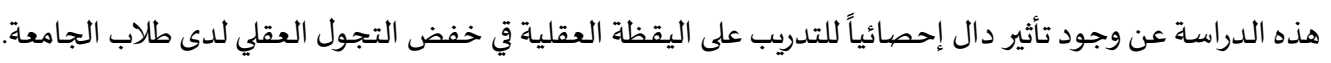

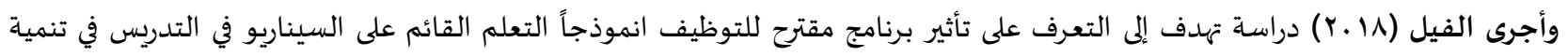

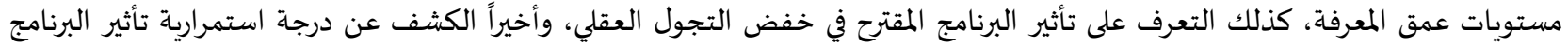

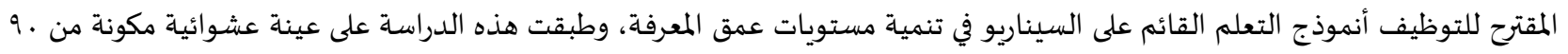

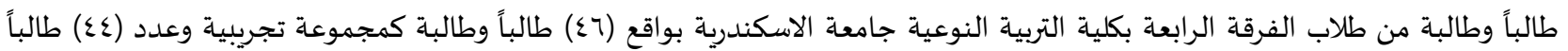

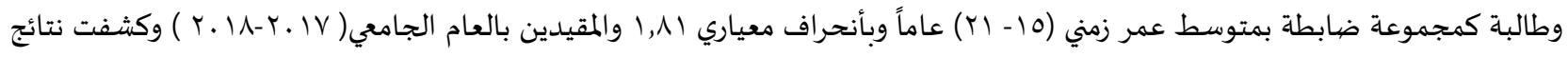
البحث عن وجود تأثير دال إحصائياً للبرنامج، في تنمية مستويات عمق المعرفة وخفض التجول التهائ العقلي لدى طلاب العينة المذكورة.

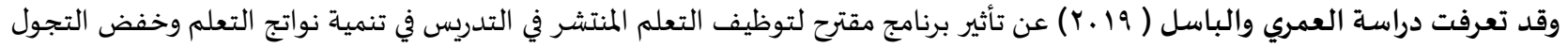

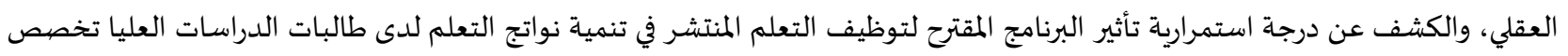

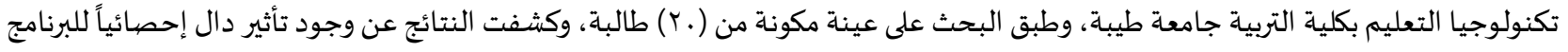

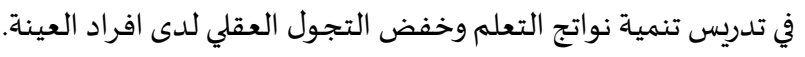

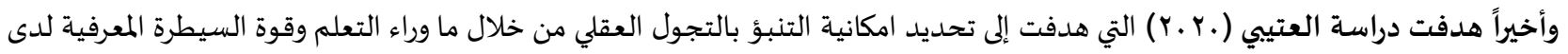

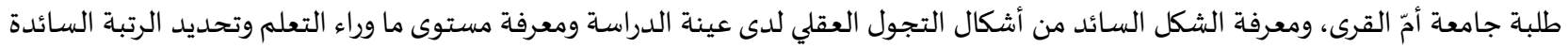

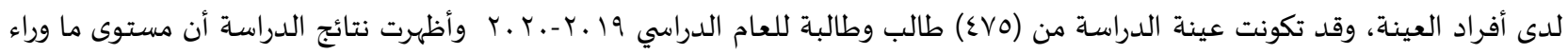
التعلم جاء بمستوِ متوسط، وأن الرتبة السائدة هي الرتبة الثانية، وأن شكل التجول العقلي السائد هو شكل أفكار مرتبطة بالمهمة.

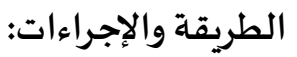
منهج البحث:

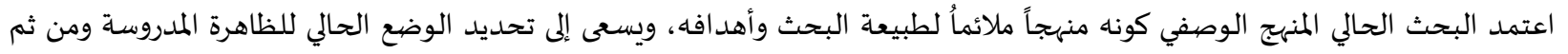

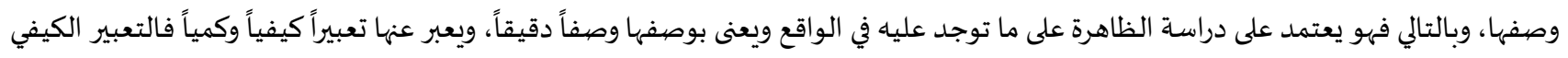

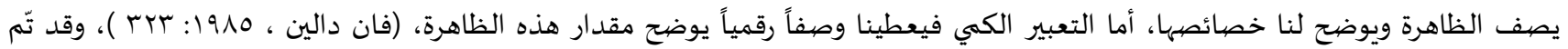

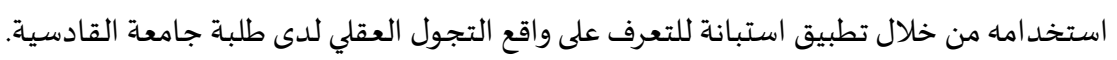
مجتمع البحث:

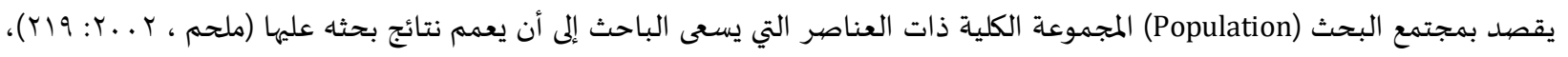

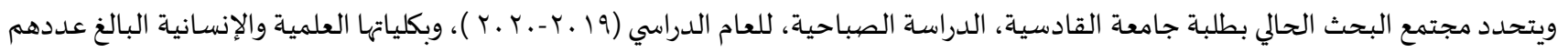

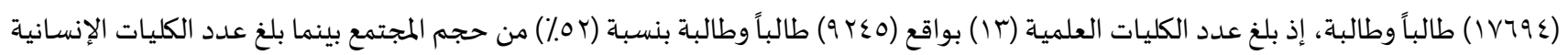

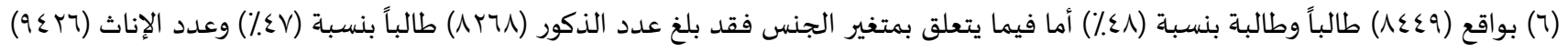

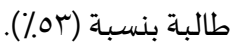
عينة البحث: تألفت عينة البحث من (. ـع) طالبا وطالبة من طلبة جامعة القادسية تم اختيارهم بالطريقة الطبقية العشوائية من المجتمع الأصلي، وجدول

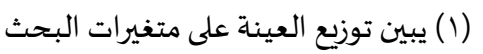


جدول(1) : توزيع العينة على متغيرات البحث

\begin{tabular}{|c|c|c|c|c|c|}
\hline المجموع & اناث انساني & ذكور انساني & اناث علمي & ذكور علمي & الكلية \\
\hline 97 & or & rq & - & - & القانون \\
\hline $1 . \varepsilon$ & - & - & 70 & $\varepsilon$. & العلوم \\
\hline 90 & 0. & $\varepsilon 0$ & - & - & الاداب \\
\hline 1.0 & - & - & 7. & $\varepsilon 0$ & الهندسة \\
\hline$\varepsilon \ldots$ & $1 . V$ & $\Lambda \varepsilon$ & ITE & 10 & المجموع \\
\hline
\end{tabular}

أدوات البحث:

أولاً: مقياس التجول العقلي: العبد:

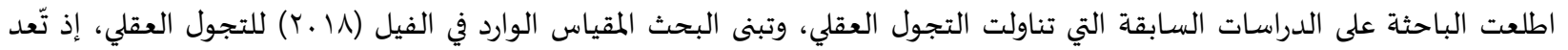

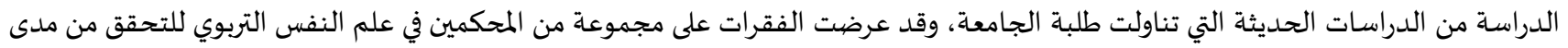
صلاحيته في البيئة العراقية. وصف المقياس: يتكون مقياس التجوال العقلي من (7) فقرة ويتكون من مجالين (Y I) فقرة ترتبط بالموضيوع (ع I) فقرة لا ترتبط بالموضوع والاجابة عليها (تنطبق

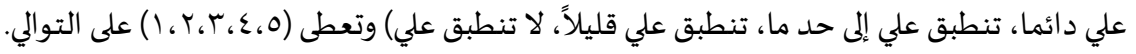
تحليل فقرات المقياس: يقصد بالقوة التمييزية للفقرات (تحليل الفقرات) هي قدرتها على التمييز بين ذوي المستويات العليا وذوي المستويات الدنيا من الأفراد في الخاصية

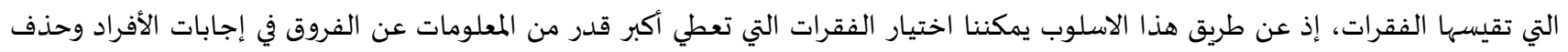

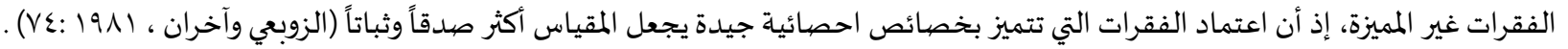
وقد اتبعت الخطوات الاتية في عملية التحليل. أ. مقياس التجول العقلي المرتبط بالموضيوع

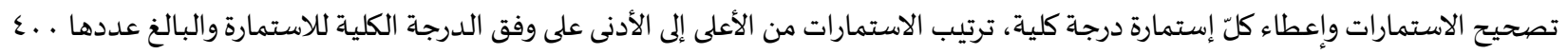

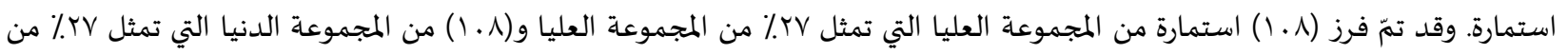

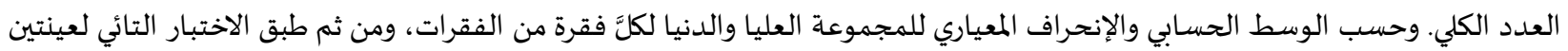

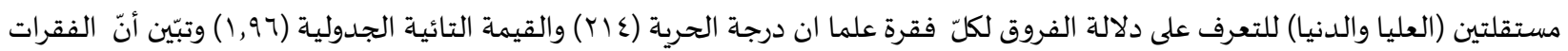

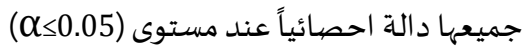

جدول(r): العينتين الطرفتين لمقياس التجول العقلي المرتبطة بالموضيوع المعاريا

\begin{tabular}{|c|c|c|c|c|c|c|}
\hline الدلالة & التائية & للمجمموعة الدنياريا & متوسط المجمموعة الدنيا & للانمرافة المعلياري & متوسط المجموعة العليا & b \\
\hline ** & $0, r r$ & r & $1,1$. & . $\leqslant 99$ & $1, \varepsilon$. & 1 \\
\hline ** & $\Lambda, .1$ & ., & $\varepsilon, Y \varepsilon$ & . , M & $r, r V$ & r \\
\hline ** & $\| 1, \varepsilon V$ & 1, & r, ro & . & $\varepsilon, 0 \mathrm{~V}$ & $r$ \\
\hline ** & $9,9 \mathrm{Y}$ & $1, .7$ & $r, \varepsilon 1$ &.,$v$. & $\varepsilon, 7 \pi$ & $\varepsilon$ \\
\hline ** & 7,00 & .,91 & $r, 1$. & ., & $r, 97$ & 0 \\
\hline ** & $11, \Lambda \varepsilon$ & $1, .1$ & T,AY & . $\mathrm{VA}$ & $\varepsilon$, rO $_{0}$ & 7 \\
\hline ** & 11, ro & $1, . \varepsilon$ & $r, T V$ & VV, & $\varepsilon, \pi T$ & V \\
\hline ** & $1 ., Y T$ & .,99 & $r, V T$ & .,$\leqslant 9$ & $\{, \lambda)$ & $\wedge$ \\
\hline ** & $1 r, .1$ & . 99 & $r, 77$ &.,$\vee \varepsilon$ & $\varepsilon, r r$ & 9 \\
\hline ** & $|r,| \Lambda$ & $1, . \mathrm{T}$ & $r, \mathrm{rA}$ & .,$\Lambda$ & $\varepsilon, r V$ & 1. \\
\hline ** & $\mid r, \varepsilon$. & ., $9 \vee$ & $r, r \varepsilon$ & זד,. & $\varepsilon, \pi T$ & 11 \\
\hline ** & $11, r$ & $1, .1$ & $r, \Sigma 1$ & ., OV & $\varepsilon, 7 V$ & IT \\
\hline
\end{tabular}


ب. مقياس التجول العقلي الغير مرتبط بالموضوع

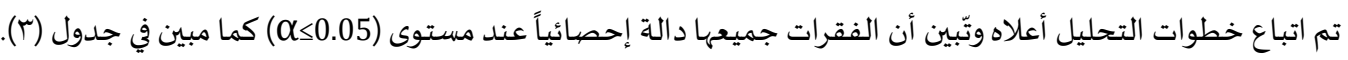

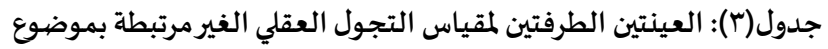

\begin{tabular}{|c|c|c|c|c|c|c|}
\hline الدلالة & التائية & للمجمموعة الدنياف المعياري & متوسط المجموعة الدنيا & للمجموعة العحراف المعياري & متوسط المجموعة العليا & م \\
\hline ** & $V, 7 V$ & .,99 & $r, \leqslant 7$ & ., 19 & $\varepsilon, \varepsilon$. & 1 \\
\hline ** & 9,91 & l,r. & $r, 0$. & $\cdot, \varepsilon \wedge$ & $\varepsilon, \wedge r$ & r \\
\hline ** & $1 r, r 9$ & 1,19 & $r, 97$ &.,$V T$ & $\varepsilon, 71$ & $r$ \\
\hline ** & $1 \varepsilon, 19$ & I,r. & $r, 19$ & $\cdot, 7$ & $\varepsilon, V \varepsilon$ & $\varepsilon$ \\
\hline ** & $1 ., 99$ & 1,11 & r,or & . & $\varepsilon, \Lambda 7$ & 0 \\
\hline ** & $11, \varepsilon \wedge$ & $\cdot, 9 \varepsilon$ & $r, \Lambda)$ & $\cdot, \wedge \mathrm{V}$ & $\varepsilon, Y \varepsilon$ & 7 \\
\hline ** & $\mid \varepsilon, 1 Y$ & $\cdot, 19$ & r,OV & $\cdot, \lambda \mathrm{V}$ & $\varepsilon, Y Y$ & $v$ \\
\hline ** & $|r, 7|$ & $\cdot, 9 \varepsilon$ & r,TV & $\cdot, \Lambda$ & $\varepsilon, r_{0}$ & $\wedge$ \\
\hline ** & $|v, 1|$ & $\cdot, \Lambda$ & r,Ar &., .7 & $\{, 71$ & 9 \\
\hline ** & IV,.0 & $1, .$. & r,vq & 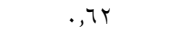 & $\varepsilon, v r$ & 1 . \\
\hline ** & $|r, r|$ &., 90 & $r, 0$. & .,9T & $\varepsilon, 19$ & 11 \\
\hline ** & $1 \mathrm{r}, 9 \mathrm{~V}$ & - ,9 & $r, 70$ & $\cdot, 91$ & $\varepsilon, \uparrow$ & ir \\
\hline & $\Lambda, \cdot r$ & $1, .1$ & $r, r)$ & . Ar & $\varepsilon, r$, & 14 \\
\hline & $\mid \gamma, \varepsilon r$ & •, AV & T,TV & ., V. & $\{, 00$ & $1 \varepsilon$ \\
\hline
\end{tabular}

الخصيائص السيكومترية للمقياس

صددق المقياس: قد تَّم استخراج نوعين من الصدق من خلال الصديدق الظاهري وصيدق البناء

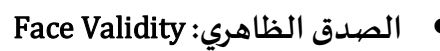

عرضت فقرات المقياس على المختصين في مجال علم النفس التربوي وعلم النفس لبيان صلاحية الفقرات في قياس ما وضعت لأجله متضمناً الهدف من الدراسة، التعريف النظري المعتمد لمتغير التجوال العقلي, لغرض إبداء آرائهم فيما يخص: أ. مدى صلاحية الفقرات لقياس ما وضعت لأجله.

ب. مدى ملائمة بد ائل الإجابة.

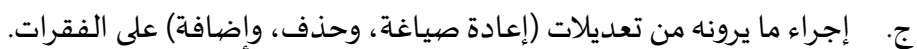

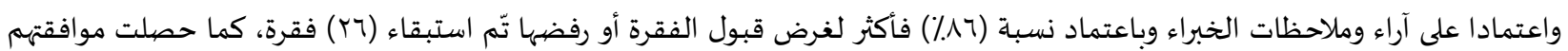

على تعليمات المقياس وبدائل الإجابة.

Construct Validity صيدق البناء

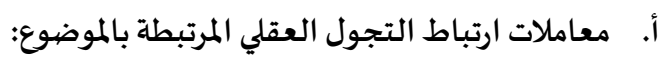

وقد تحقق صدق بناء مقياس التجوال العقلي من خلال التعرف على معاملات الارتباط التي تربط بين كل فقرة بدرجة المجال. وقد كانت فقرات

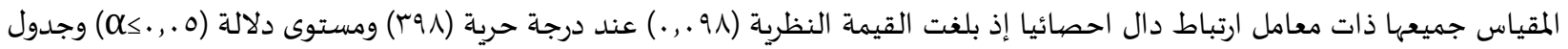
(ع) وجدول (0) يبيان ذلك.

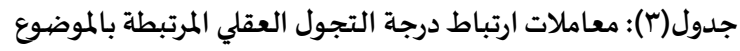

\begin{tabular}{|c|c|c|c|}
\hline معامل الارتباط & تسلسل الفقرة & معامل الارتباط & م م \\
\hline., 01 & V &.,$Y T$ & 1 \\
\hline ., १ᄉ & 1 &., 49 & $r$ \\
\hline .07 & 9 &., $0 \varepsilon$ & $r$ \\
\hline., $0 \leqslant$ & 1. &.,$\leqslant 9$ & $\varepsilon$ \\
\hline., 01 & 11 & . Tr & 0 \\
\hline , or & IT &., 00 & 7 \\
\hline
\end{tabular}


ب. معاملات ارتباط التجول العقلي غير المرتبطة بالموضوع

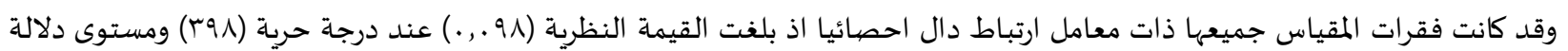

جدول(0): معاملات ارتباط درجة التجول العقلي الغير مرتبطة بالموضيوع

\begin{tabular}{|c|c|c|c|}
\hline معامل الارتباط & تسلسل الفقرة & معامل الارتباط & م \\
\hline .,OY & $\wedge$ & . ro & 1 \\
\hline., 71 & 9 &., $0 \mathrm{~V}$ & $r$ \\
\hline ., Or & 1. & זד, - & $r$ \\
\hline ., V. & 11 & .,70 & $\varepsilon$ \\
\hline.,$V \varepsilon$ & Ir & . & 0 \\
\hline., 00 & $1 \pi$ & .,OT & 7 \\
\hline .,01 & $1 \varepsilon$ & . & $v$ \\
\hline
\end{tabular}

ثبات المقياس:

للتعرف على ثبات مقياس التجول العقلي لجأت الباحثة إلى طريقة الاتساق الداخلي للتأكد بشكل أكثر دقة من درجة ثبات هذا المقياس في قياس

التجول العقلي وفيما يأتي وصف للطريقة التي اتبعت في تحقيقها.

• • طريقة الاتساق الداخلي (باستخدام معادلة الفا كرونباخ):

تقوم فكرة هذه الطريقة على حساب الارتباطات بين درجات المقياس جميعها على أساس أنساست الفقرة تعدُّ مقياساً قائماً بذاته ويؤشر الثبات وفق هذه الطريقة اتساق أداء المستجيب بين فقرات المقياس وتعد هذه الطريقة من أكثر الطرائق شيوعاً إذ تمتاز بأمكانية الوثوق بنتائجها (عودة

والخليلي، ولاستخراج الثبات بهذه الطريقة اعتمدت الباحثة معادلة (الفا كرونباخ) لحساب الارتباطات بين درجات الفقرات لافراد عينة البحث، وقد بلغ

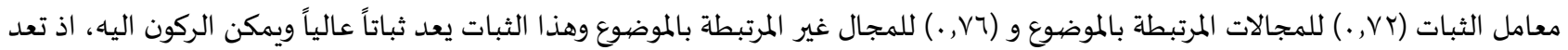

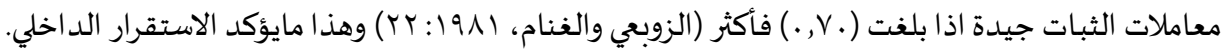

الوسائل الاحصيائية المستخدمة

الاختبار التائي لعينة واحدة: لتعرف دلالة الفرق بين المتوسط الحسابي والمتوسط الفرضي على مقياس التجول العقلي.

الاختبار التائي لعينتين مستقلتين لاستخراج القوة التمييزية لفقرات مقاييس البحث باسلوب المجموعتين الطرفيتين

تحليل التباين الثنائي للتعرف على دلالة الفروق في التجول العقلي المرتبط بالموضوع تبعا لمتغير الجنس (ذكور-اناث) ومتغير التخصص (علمي-

(انساني)

\section{النتائج ومناقشتها}

النتائج المتعلقة بالإجابة عن السؤال الأول ونصيه "ما واقع التجول العقلي لدى طلبة جامعة القادسية في العراق؟" للإجابة عن السؤال السابق تم

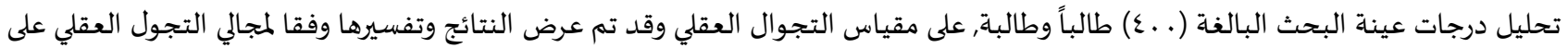
النحو التالي: أ. النتائج المتعلقة بالتجول العقلي المرتبط بالموضيوع لدى طلبة جامعة القادسية: تبين أنَّ الوسط الحسابي لواقع التجول العقلي المرتبط بالموضوع

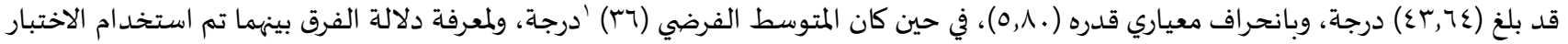

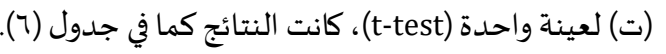

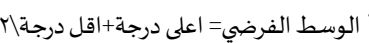

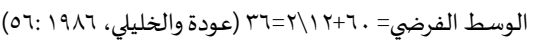


جدول(7): اختبار (ت) للفرق بين المتوسط المحسوب والمتوسط الفرضي لمقياس التجول العقلي المرتبط بالموضيوع

\begin{tabular}{|c|c|c|c|c|c|c|c|}
\hline مستوى الدلالة & الجدولية & قيمة & الحربة & المتوسطي & المعياري & المستوسط الحسب & العينة \\
\hline., .0 & 1,97 & $\gamma, 7 \varepsilon$ & $r 99$ & $r$ & $0, \Lambda$. & $\varepsilon r, 7 \varepsilon$ & $\varepsilon$. \\
\hline
\end{tabular}

يبين جدول (7) وجود فرق دال إحصائياً (1)0.05) باتجاه الوسط الفرضي, إذ بلغت قيمة (ت) المحسوبة (ع,7) وهذا يشير إلى إن طلبة الجامعة

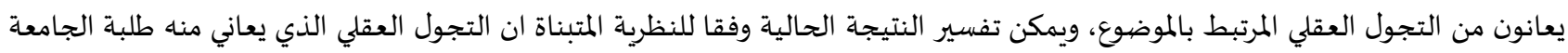

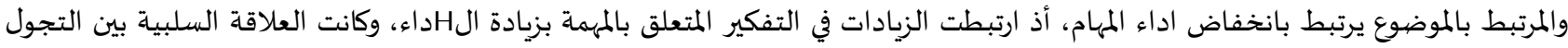

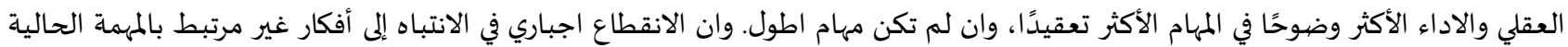
ولكنها مرتبطة بموضوعات المادة الدراسية والتي تحدث بشكل تلقائي.

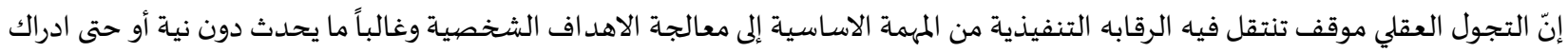
عقل المرء، تشير الابحاث إلى أنّ ما يقارب من نصف أفكار الحياة اليومية (تجول عقلي) وان هذه الظاهرة تحدث بشكل متكرر في جميع أشكال

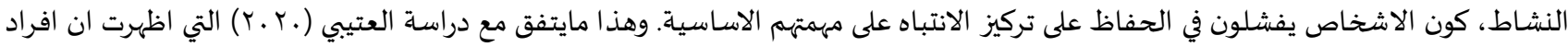

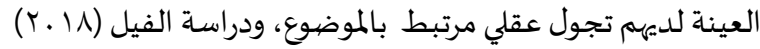

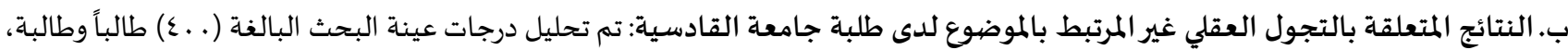

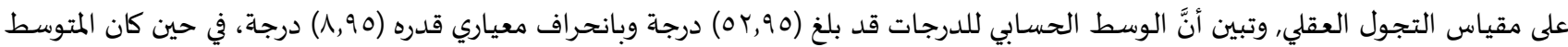

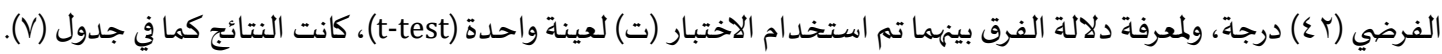

\begin{tabular}{|c|c|c|c|c|c|c|c|}
\hline مستوى الدلالة & الجدوليمة & التائية & الحرجة & المترضي & المعياري & المسابي & العدد \\
\hline., .0 & 1,97 & $T \varepsilon, \varepsilon_{0}$ & $r 99$ & $\varepsilon r$ & 1,90 & $0 r, 90$ & $\varepsilon \ldots$ \\
\hline
\end{tabular}

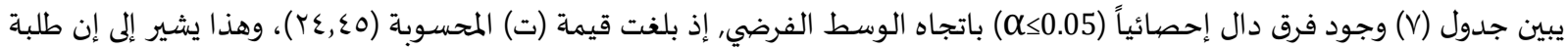

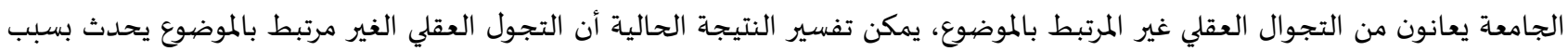
تكريس الاهتمام الابرز في تجارب الافراد او مخاوف ذات حافز شخصي أعلى في هذه الحالات، فأن بداية التجول العقلي أثناء أداء المهمة سيحدث

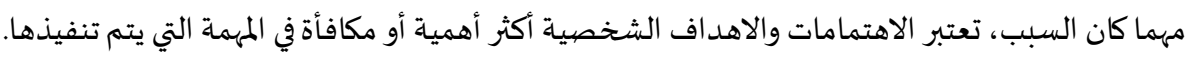
وأن التجول العقلي، يحدث بصورة منفصلة عن البيئة الخارجية وبالتالي تتنامى بشكل مستقل مع الخارجية واداء المهمة للتركيز المعتمد. وأن أنان

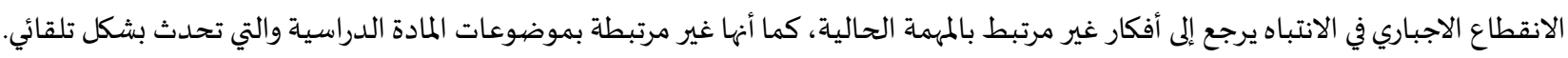

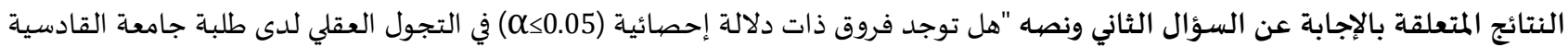
يعزى لمتغير الجنس أو التخصص؟" تم تناول إجابة السؤال السابق وتفسيرها وفقا لكل مجال من مجالات التجول العقلي ووفقا لمتغيري الجنس إنس

والتخصص على النحو التالي: أ. النتائج المتعلقة بالتجول العقلي المرتبط بالموضيوع لدى طلبة جالئ جامعة القادسية تبعاً لمتغيري الجنس والتخصص: تم استخدام تحليل التباين

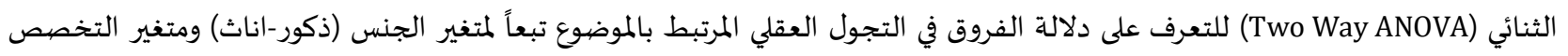
(علمي-انساني)، وجدول (ᄉ) يبين نتائج التحليل.

\begin{tabular}{|c|c|c|c|c|c|}
\hline الإحصائية & $\begin{array}{l}\text { قيمة } \\
\text { (F) }\end{array}$ & متوسط المربعات & الحربة & المربعات & التباين \\
\hline غير دالة &., 19 & $7, \mathrm{VI}$ & 1 & $7, \sqrt{71}$ & الجنس \\
\hline غير دالة & r, rq & $V V, r_{0}$ & 1 & $V V, r_{0}$ & التخصص \\
\hline \multirow[t]{3}{*}{ غير دالة } &., 11 & 7,11 & 1 & 7,11 & الجنسX التخصص \\
\hline & & $r r, 7 q$ & r97 & (ז & الخطأ \\
\hline & & & $\varepsilon$. & Vroriv & الكلي \\
\hline
\end{tabular}




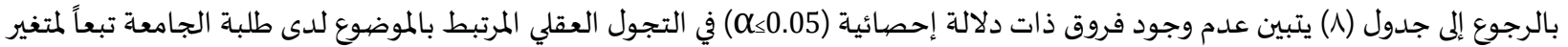

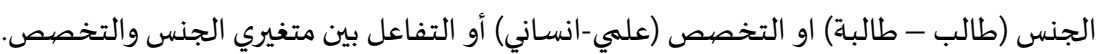
ب. النتائج المتعلقة بالتجول العقلي غير المرتبط بالموضيوع لدى طلبة جامعة القادسية تبعاً لمتغيري الجنس والتخصص: تمَّ استخدام تحليل التباين الثنائي (Two Way ANOVA) للتعرف على دلالة الفروق في التجول العقلي غير المرتبط بالموضوع تبعاً لمتغير الجنس (ذكور-اناث) ومتغير التخصص (علمي-انساني)، وجدول (9) يبين نتائج التحليل.

\begin{tabular}{|c|c|c|c|c|c|}
\hline الإحصائية & $\begin{array}{l}\text { قيمة } \\
\text { (F) }\end{array}$ & متوسط المربعات & دالحرجة & المجربعات & مصددر \\
\hline غير دالة &., 70 & or,..\& & 1 & or,.. & الجنس \\
\hline غير دالة &., $\mathrm{VI}$ & OV, 17 & 1 & $0 V, 77$ & التخصص \\
\hline \multirow[t]{3}{*}{ غير دالة } &., .1 &., .7 & 1 &., .7 & الجنس X التخصص \\
\hline & & A.,OY & r97 & 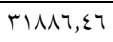 & الخطأ \\
\hline & & & $\varepsilon \ldots$ & $110 r \varepsilon \Lambda 1$ & الكلي \\
\hline
\end{tabular}

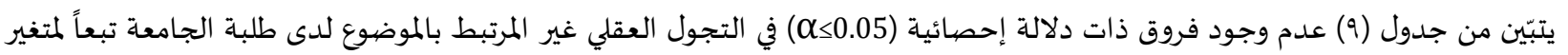

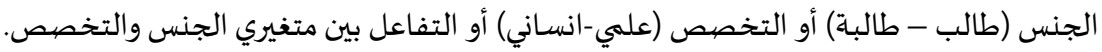

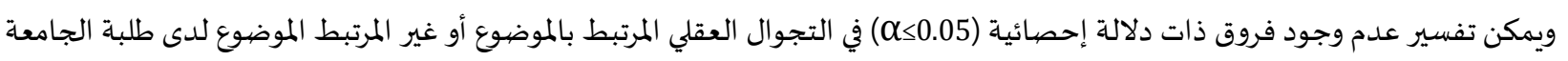

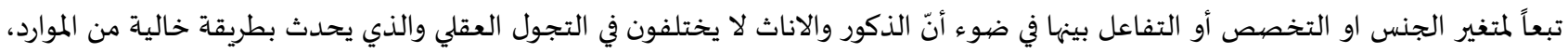

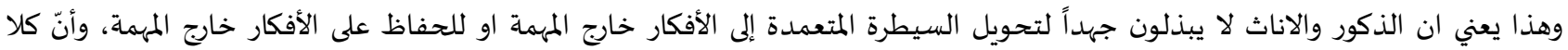

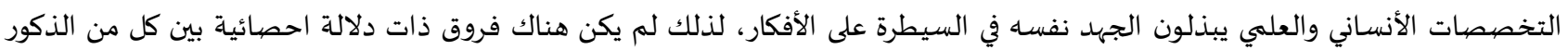

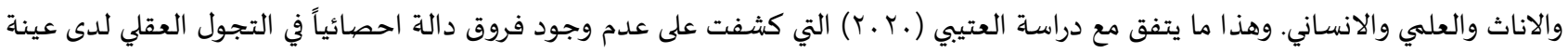
الدراسـة تبعاً للنوع.

في ضوء النتائج التي توصل إلها البحث ، فإن أهم ما توصي باه الباحثة ما يلي:

تشجيع المختصين على إقامة ندوات عن ظاهرة التجول العقلي والتعرف على أهم سلبيات وإيجابيات التجول العقلي عن عملية التعلم. عقد دورات علمية متخصصة تشرح للأساتذة بالتفصيل عن كيفية التعرف على التجول العقلي الحاصل لدى الطلبة وشرح سبل التخلص منها. تنويع وتطوير طرق التدريس المقدمة من لدن الاساتذة والابتعاد عن الطرق الكلاسيكية.

المقترحات:

تقترح الباحثة ما يلي:

إجراء بحث للتعرف على اثر برنامج مقترح قائم على استراتيجيات التعلم العميق على خفض حدة التجول العقلي في ضوء مستوى مطالب المهمة. إجراء بحث نمذجة العلاقات بين التجول العقلي ومهارات التفكير الإبداعي ومهارات حل المشكلات المستقبلية. إجراء بحث يتحرى عن علاقة التجول العقلي مع التفكير الإبداعي وحل المشكلات إجراء بحث للتعرف على العوامل المؤثرة على التجول العقلي.

ا. الزوبعي، عبد الجليل وبكر، محمد الياس الكناني، عبد الحسن. (1919). الاختبل ات والمقايسيس النفسية. ط ا ـ دار الكتب للطباعة والنشر. جامعة الموصل. r. عبد الحافظ، ثناء عبد الودود. (7 ا ـ r). الانتباه التنفيذي والوظيفة التنفيذية. دار من المحيط إلى الخليج للنشرو التوزع. ط ا. عمان. 


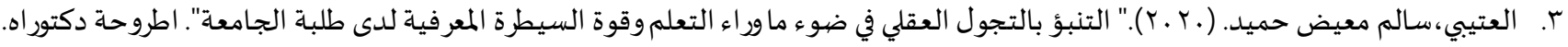
جامعة ام القرى. كلية التربية.

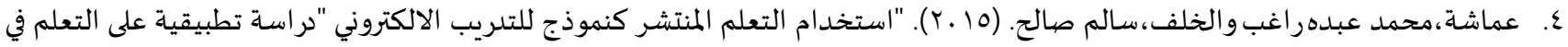

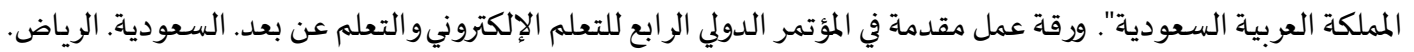

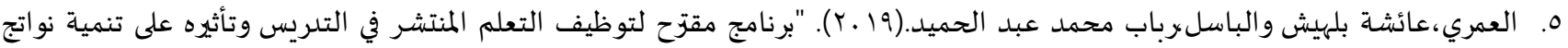

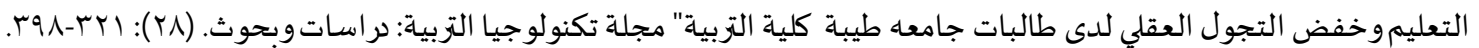

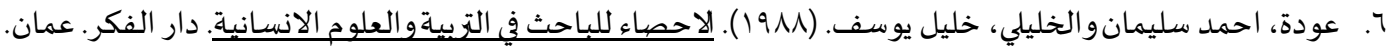

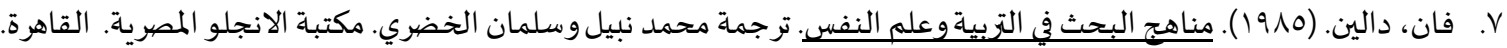

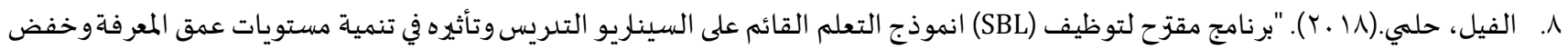

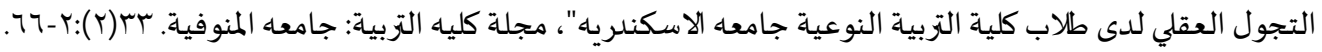

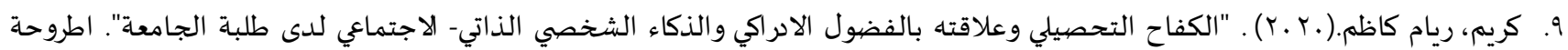
دكتوراة غير منشورة. الجامعة المستنصرية. كلية الزبية.

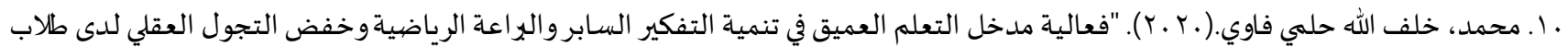

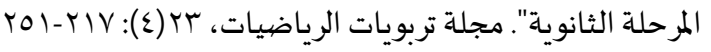

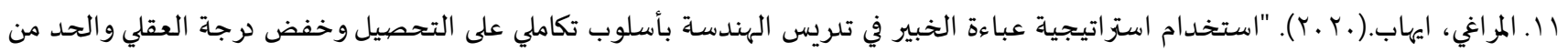

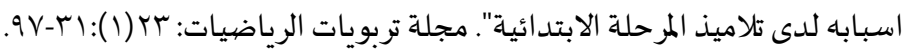

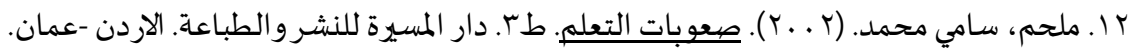

ثانياً: المراجع الأجنبية:

[1] Acai, A. (2016). "What Are Residents Paying Attention To? An Exploration of Mind Wandering During Classroom-Based Teaching Sessions (Academic Half-Days) in Postgraduate Medical Education" (Doctoral dissertation).

[2] Baars, B. J. (2010). "Spontaneous repetitive thoughts can be adaptive: Postscript on "mind wandering". Psychological bulletin. 136(2): 208-210, https://doi.org/10.1037/a0018726.

[3] Baird, B., Smallwood, J., \& Schooler, J. W. (2011). "Back to the future: Autobiographical planning and the functionality of mind-wandering". Consciousness and cognition.20(4): 1604-1611, https://doi.org/10.1016/j.concog.2011.08.007.

[4] Bell, B. S., Wiechmann, D., \& Ryan, A. M. (2006). "Consequences of organizational justice expectations in a selection system". Journal of Applied Psychology. 91(2): 455, https://doi.org/10.1037/0021-9010.91.2.455.

[5] Brel \& B. T (2004)" The role of 3-dimentional state goal orientation in the process of goal establishment and task performance". (Doctoral dissertation, Virinia Tech).

[6] Engle, R. W., \& Kane, M. J. (2004). "Executive attention, working memory capacity, and a two-factor theory of cognitive control. In B. Ross (Ed.)", The psychology of learning and motivation, (pp.145-199) NY: Academic Press.

[7] Forster, S., \& Lavie, N. (2009). "Harnessing the wandering mind: The role of perceptual load". Cognition, 111(3), 345-355, https://doi.org/10.1016/j.cognition.2009.02.006.

[8] Forster, S., \& Lavie, N. (2013). "Distracted by your mind? Individual differences in distractibility predict mind wandering". Journal of Experimental Psychology: Learning, Memory, and Cognition. 40(1):251-260, https://doi.org/10.1037/a0034108.

[9] Kane. M. J. \& McVay. J. C. (2012). "What Mind Wandering Reveals About Executive-Control Abilities and Failures". Current Directions in Psychological Science. 21(5):348-354, https://doi.org/10.1177/0963721412454875.

[10] KillingsWorth, M \& Gilbert, D. (2010). "A Wandering Mind Is an Unhappy Mind”. Science. 330(6006): 932, https://doi.org/10.1126/science.1192439

[11] Levinson, D; Smallwood, J.; Davidson, RJ (2011). "The persistence of thought". Psychological Science. 23 (4): $375-380$.

[12] Levinson, D. B., Smallwood, J., \& Davidson, R. J. (2012). "The persistence of thought: Evidence for a role of working memory in the maintenance of task-unrelated thinking". Psychological Science. 23:375-380.

[13] Londeree, A. (2015). "Mindfulness and Mind- Wandering in Older Adults: Implications for Behavioral Performance". Master Thesis, Ohio State University. 
[14] Luo, Y., Zhu, R., Ju, E., \& You, X. (2016). “Validation of the chinese version of the mind-wandering questionnaire (MWQ) and the mediating rple of self-esteem in the relationship between mind-wandering and the life satisfaction for adolescents". personality and individual differences. 92: pp 118 -122, https://doi.org/10.1016/j.paid.2015.12.028.

[15] McVay, J. C., \& Kane, M. J. (2012b). "Why does working memory capacity predict variation in reading comprehension? On the influence of mind-wandering and executive attention". Journal of Experimental Psychology: General. 141(2): 302320, https://doi.org/10.1037/a0025250.

[16] Mrazek, M., Phillips, D., Franklin, M., Broadway, J. \& Schooler, J. (2013). "Young and restless: validation of the Mind Wandering Questionnaire (MWQ) reveals disruptive impact of mind- Wandering for youth". Frontiers in Psychology. 4: 16, https://doi.org/10.3389/fpsyg.2013.00560.

[17] Rahal, H., Lindsay, E., Pacilio, L., Brown, K., \& Creswell, J. (2017). “Brief Mindfulness Meditation Training Reduces Mind Wanering: The Critical Role of Acceptance”. American Psychological Association,1

[18] Randall, J. (2015). "Mind Wandering and Self -directed learning: Testing the Efficiency of Self -Regulation Interventions to Reduce Mind wandering and Enhance online Training Performance”. PhD. Dissertation, Rice University.

[19] Risk, E., Anderson, N., Sarwal, A., Engelhardt \& Kingstone, A. (2012). "Everyday Attention: Variation in Mind Wandering and Memory in a lecture". Applied Cognitive Psychology. 26(2): 234-242, https://doi.org/10.1002/acp.1814.

[20] Rodríguez -Villagra, Odir Antonio;Göthe, Katrin; Oberauer, Klaus \& Kliegl, Reinhold (2013). "Working memory capacity in a go/no-go task: Age differences in interference, processing speed, and attentional control". Developmental Psychology. 49(9): 1683-1696, https://doi.org/10.1037/a0030883.

[21] Small Wood, J., \& Schooler, J. (2006). “The Restless mind”. Psychological Bulletin,132,94.

[22] Small Wood, J., Obonsawin, M. \& Reid, H. (2003). "Task unrelated thought: The Role of block duration". Imagination. Cognition and Personality, 21 (4): 319-332.

[23] Smallwood, J., O'connor, R., Sudberry, M.V., Ballantyre, C. (2004). "The consequences of encoding in formation on the maintenoaucee of internally generated images and thoughts: the role of meaning complexes". Consciousness and cognition, 13(4): 789-820, https://doi.org/10.1016/j.concog.2004.07.004.

[24] Smallwood, J., \& Schooler, J. W. (2015). "The science of mind wandering: empirically navigating the stream of consciousness". Annual review of psychology. 66(1): 487-518, https://doi.org/10.1146/annurev-psych-010814-015331.

[25] Smith, T. E., Finn, D. M., \& Dowdy, C. A. (1993). Teaching students with mild disabilities. 
المجلة الدولية للدراسـات التربوية والنفسية

International Journal of Educational \& Psychological Studies (EPS)

Journal Homepage: https://www.refaad.com/views/EPSR/Home.aspx

www.refaad.com
ISSN : 2520-4149 (Online) 2520-4130 (Print)

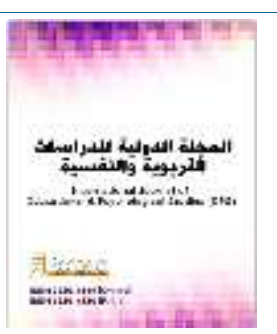

\title{
The reality of mental wandering among university students in Iraq in light of some variables
}

\author{
Zina Nizar \\ Assistant Lecturer in the Department of Psychology, Al-Qadisiyah University, Iraq \\ Zina.aljanabi@qu.edu.iq
}

\begin{abstract}
Mental wandering is the failure of some students to maintain their focus on their own thoughts and activities related to the current task, and this failure is due to a portion of external and internal stimuli that interfere to attract attention away from the task, and this is what prompted the current researcher to know mental wandering among students of Al-Qadisiyah University, and the differences According to the gender (male-female) and specialization (scientific-human), and to achieve this, the researcher adopted the mental wandering scale (The Elephant, 2018) after its psychometric characteristics were extracted, and the scale was applied to a sample of (400) students from Al-Qadisiyah University in Iraq The results found that students at Qadisiyah University had a mental wandering related to the topic and another not related to the topic. The research recommended the necessity of holding seminars and courses dealing with learning about mental wandering and ways to get rid of it, and the necessity of sustaining innovative approaches in teaching students and moving away from classical methods.
\end{abstract}

\section{Keywords: mental wander; attention; students of Al-Qadisiyah University.}

\section{References:}

[1] Alzwb'y, 'bd Aljlyl Wbkr, Mhmd Alyas Walknany, 'bd Alhsn. (1981). Alakhtbarat Walmqayys Alnfsyh. T1. Dar Alktb Lltba'h Walnshr. Jam't Almwsl.

[2] 'bd Alhafz, Thna' 'bd Alwdwd. (2016). Alantbah Altnfydy Walwzyfh Altnfydyh. Dar Mn Almhyt Ela Alkhlyj Llnshr Waltwzy'. T1. 'man.

[3] Al'tyby,Salm M'yd Hmyd. (2020)." Altnb' Baltjwl Al'qly Fy Dw' Ma Wra' Alt'elm Wqwh Alsytrh Alm'rfyh Lda Tlbh Aljam'h". Atrwht Dktwrah. Jam't Am Alqra. Klyt Altrbyh.

[4] 'mashh,Mhmd 'Ebdh Raghb Walkhlf,Salm Salh. (2015). "Astkhdam Alt'lm Almntshr Knmwdj Lltdryb Alalktrwny "Drash Ttbyqyh 'la Alt'lm Fy Almmlkh Al'rbyh Als'wdyh". Wrqt 'ml Mqdmh Fy Alm'tmr Aldwly Alrab' Llt'lm Alelktrwny Walt'lm 'n B'ed. Als'wdyh. Alryad.

[5] Al'mry,'a'shh Blhysh Walbasl,Rbab Mhmd 'bd Alhmyd.(2019). "Brnamj Mqtrh Ltwzyf Alt'lm Almntshr Fy Altdrys Wtathyrh 'la Tnmyt Nwatj Alt'lym Wkhfd Altjwl Al'qly Lda Talbat Jam't Tybh Klyt Altrbyh" Mjlt Tknwlwjya Altrbyh: Drasat Wbhwth. (28): 321-398.

[6] 'wdh, Ahmd Slyman Walkhlyly, Khlyl Ywsf. (1988). Alahsa' Llbahth Fy Altrbyh Wal'lwm Alansanyh. Dar Alfkr. 'man.

[7] Fan, Dalyn. (1985). Mnahj Albhth Fy Altrbyh W'lm Alnfs. Trjmt Mhmd Nbyl Wslman Alkhdry. Mktbt Alanjlw Almsryh. Alqahrh.

[8] Alfyl, Hlmy. (2018). "Brnamj Mqtrh Ltwzyf (Sbl) Anmwdj Alt'lm Alqa'm 'la Alsynaryw Altdrys Wtathyrh Fy Tnmyt Mstwyat 'mq Alm'rfh Wkhfd Altjwl Al'qly Lda Tlab Klyt Altrbyh Alnw'yh Jam't Alaskndryh", Mjlt Klyt Altrbyh: Jam't Almnwfyh. 33(2):2-66.

[9] Krym, Ryam Kazm.(2020) . "Alkfah Althsyly W'laqth Balfdwl Aladraky Waldka' Alshkhsy Aldaty- Alajtma'y Lda Tlbh Aljam'h". Atrwht Dktwrah Ghyr Mnshwrh. Aljam'h Almstnsryh. Klyt Altrbyh.

[10] Mhmd, Khlf Allh Hlmy Fawy.(2020). "F'alyh Mdkhl Alt'lm Al'myq Fy Tnmyt Altfkyr Alsabr Walbra'h Alryadyh Wkhfd Altjwl Al'qly Lda Tlab Almrhlh Althanwyh". Mjlh Trbwyat Alryadyat, 23(4): 217-251.

[11] Almraghy, Ayhab.(2020). "Astkhdam Astratyjyh 'ba'h Alkhbyr Fy Tdrys Alhndsh Baslwb Tkamly 'la Althsyl Wkhfd Drjt Al'qly Walhd Mn Asbabh Lda Tlamyd Almrhlh Alabtda'yh". Mjlt Trbwyat Alryadyat: 23(1):31-97.

[12] Mlhm, Samy Mhmd. (2002). S'ewbat Alt'lm. T3. Dar Almsyrh Llnshr Waltba'h. Alardn -'man. 